\title{
iTRAQ-Based Proteomics Identification of Serum Biomarkers of Two Chronic Hepatitis B Subtypes Diagnosed by Traditional Chinese Medicine
}

\author{
Jiankun Yang, ${ }^{1}$ Lichao Yang, ${ }^{2}$ Baixue Li, ${ }^{1}$ Weilong Zhou, ${ }^{3}$ Sen Zhong, ${ }^{4}$ Zhenhua Zhuang, \\ Bin Yang, ${ }^{5}$ Maoshan Chen, ${ }^{6}$ and Quansheng Feng ${ }^{1}$ \\ ${ }^{1}$ Chengdu University of Traditional Chinese Medicine, Chengdu 610075, China \\ ${ }^{2}$ Handan Chinese Medicine Hospital, Handan 056001, China \\ ${ }^{3}$ West China Hospital, Sichuan University, Chengdu 610041, China \\ ${ }^{4}$ Affiliated Hospital of Chengdu University of Traditional Chinese Medicine, Chengdu 610075, China \\ ${ }^{5}$ Chengdu Life Baseline Technology, Chengdu 610041, China \\ ${ }^{6}$ Department of Biochemistry and Genetics, La Trobe Institute for Molecular Science (LIMS), La Trobe University, \\ Melbourne, VIC 3086, Australia
}

Correspondence should be addressed to Quansheng Feng; fengquansheng@cdutcm.edu.cn

Received 18 July 2016; Accepted 24 October 2016

Academic Editor: Yasunobu Matsuda

Copyright (C) 2016 Jiankun Yang et al. This is an open access article distributed under the Creative Commons Attribution License, which permits unrestricted use, distribution, and reproduction in any medium, provided the original work is properly cited.

\begin{abstract}
Background. Chronic infection with hepatitis B virus (HBV) is a leading cause of cirrhosis and hepatocellular carcinoma. By traditional Chinese medicine (TCM) pattern classification, damp heat stasis in the middle-jiao (DHSM) and liver Qi stagnation and spleen deficiency (LSSD) are two most common subtypes of CHB. Results. In this study, we employed iTRAQ proteomics technology to identify potential serum protein biomarkers in $30 \mathrm{LSSD}-\mathrm{CHB}$ and $30 \mathrm{DHSM}-\mathrm{CHB}$ patients. Of the total 842 detected proteins, 273 and 345 were differentially expressed in LSSD-CHB and DHSM-CHB patients compared to healthy controls, respectively. LSSD-CHB and DHSM-CHB shared 142 upregulated and 84 downregulated proteins, of which several proteins have been reported to be candidate biomarkers, including immunoglobulin (Ig) related proteins, complement components, apolipoproteins, heat shock proteins, insulin-like growth factor binding protein, and alpha-2-macroglobulin. In addition, we identified that proteins might be potential biomarkers to distinguish LSSD-CHB from DHSM-CHB, such as A0A0A0MS51_HUMAN (gelsolin), PON3_HUMAN, Q96K68_HUMAN, and TRPM8_HUMAN that were differentially expressed exclusively in LSSD-CHB patients and A0A087WT59_HUMAN (transthyretin), ITIH1_HUMAN, TSP1_HUMAN, CO5_HUMAN, and ALBU_HUMAN that were differentially expressed specifically in DHSM-CHB patients. Conclusion. This is the first time to report serum proteins in CHB subtype patients. Our findings provide potential biomarkers can be used for LSSD-CHB and DHSM-CHB.
\end{abstract}

\section{Introduction}

Chronic hepatitis B virus ( $\mathrm{CHB}$ ) infection is a leading cause of cirrhosis and hepatocellular carcinoma (HCC) and, in addition to morbidity and mortality, creates significant economic and social burdens $[1,2]$. It is estimated that approximately 240 million people have $\mathrm{CHB}$ infection worldwide and CHB infection should be responsible for 650,000 cases of hepatocellular carcinoma $[2,3]$. Due to the pathogenicity of
$\mathrm{CHB}$, early detection of $\mathrm{CHB}$ infection is the goal of treatment to diagnose and prevent the progression [4]. To this end, several hepatitis B virus (HBV) markers have been identified, including antigens (hepatitis B surface antigen, HBsAg; hepatitis $\mathrm{Be}$ antigen, $\mathrm{HBeAg}$; hepatitis $\mathrm{B}$ core antigen, $\mathrm{HBcAg}$ ), antibodies (hepatitis surface antibody, anti-HBs; hepatitis Be antibody, anti-HBe; hepatitis B core antibody, anti-HBc), and immunoglobulin (Ig) G and immunoglobulin M; however, unequivocal diagnosis requires more biomarkers [5]. 
By traditional Chinese medicine (TCM) pattern classification, $\mathrm{CHB}$ infected patients are accordingly classified into six subtypes [6]: (1) damp heat stasis in the middlejiao (DHSM), (2) liver Qi stagnation and spleen deficiency (LSSD), (3) Yang deficiency of spleen and kidney (YDSK), (4) Yin deficiency of liver and kidney (YDLK), (5) blood stasis into collateral (BSIC), and (6) damp heat complicated with blood stasis (DHBS). Among them DHSM and LSSD are two most common $\mathrm{CHB}$ subtypes and have unique syndromes in clinic. For example, LSSD patients always have main syndromes, such as (Mi) flank pain and (Mii) abdominal distension and loose stools, and secondary symptoms, including ( $\mathrm{Si}$ ) depression and boredom, (Sii) body tired fatigue, and (Siii) pale tongue with teeth marks. DHSM patients have another two main syndromes, such as (M1) abdominal distension and (M2) yellow greasy moss, and three secondary syndromes, including (S1) nausea, being tired of the oil, and poor appetite, (S2) jaundice, bright color, and dark urine, and (S3) viscous stool foul smell. However, these syndromes are diagnosed by TCM doctors according to their experiences and the molecular biomarkers remain unclear.

Proteomics is a powerful technology recently developed to enhance our study on the diagnosis, treatment, and prevention of human diseases [7]. Among the proteomics technologies iTRAQ (isobaric Tags for Relative and Absolute Quantitation) has become popular for protein identification and quantification due to its sensitivity, accuracy, and high throughput [8]. It has been used to identify biomarker proteins for different stages of hepatitis B related diseases in patients and cellular models [9-12]. Several serum proteins have been reported to be potential biomarkers for $\mathrm{CHB}$, such as actin [13], apolipoproteins A-I and A-IV [14], complement component [15], immunoglobulin related proteins $[15,16]$, haptoglobins $\beta$ and $\alpha 2$ chain [14], and transferrin [17].

In this study, we employed iTRAQ combined with LCESI-MS/MS analyses to investigate protein biomarkers in the serum samples of two CHB subtype patients (LSSD and DHSM). Compared to healthy controls we found a number of proteins differentially expressed in both LSSD and DHSM CHB subtypes, such as actin, apolipoprotein, complement component, and immunoglobulin related proteins. In addition, we identified some proteins differentially expressed exclusively in one of LSSD and DHSM groups, such as gelsolin (GSN), likely SNC73 protein, and transient receptor potential cation channel subfamily $M$ member 8 (TRPM8) that were found with different expression in LSSDCHB patients only and transthyretin (TTR), tubulin, and keratin types I and II that were differentially expressed in DHSM-CHB patients only. Our findings not only validate previously reported $\mathrm{CHB}$ protein biomarkers but also report for the first time protein biomarkers for LSSD and DHSM $\mathrm{CHB}$ subtypes. The output of this study gives a valuable resource for future $\mathrm{HBV}$ associated studies and provides new insights of traditional Chinese medicine on molecular level.

\section{Materials and Methods}

2.1. Ethics Statement. This study was conducted in compliance with the Declaration of Helsinki, the ethics approval was granted by the research medical ethics committee of Chengdu University of Traditional Chinese Medicine, and signed informed consent was obtained from all participants.

\subsection{Patients and Serum Collection. A total of $104 \mathrm{CHB}$} patients were enrolled from West China Hospital, Sichuan University, and filtered with strict clinical evaluation described below. For iTRAQ proteomics analysis, we obtained blood samples from 30 LSSD-CHB patients, 30 DHSM-CHB patients, and 20 healthy controls (HCTL). For western blot analysis, 9 LSSD-CHB patients, 9 DHSM-CHB patients, and $6 \mathrm{HCTL}$ participants were enrolled. Serum was collected from blood sample $(4 \mathrm{~mL})$ following the manufacture's protocol. Briefly, blood sample was incubated at room temperature for $2 \mathrm{~h}$ in vacutainer blood handling tube (Becton Dickinson, New Jersey, USA) and centrifuged for $10 \mathrm{~min}$ at $3,000 \mathrm{rpm}$ and $4^{\circ} \mathrm{C}$. Serum sample, which is the result supernatant, was transferred into a clean polypropylene tube and stored at $-80^{\circ} \mathrm{C}$.

2.3. Clinical Evaluation. The viral markers $\mathrm{HBsAg}, \mathrm{HBeAg}$, anti-HBs, anti-HBc, and anti-HBe were determined routinely in serum samples using standard procedures (AxSYM ${ }^{\circledR}$; Abbott Laboratories, Rungis, France), as well as other molecular diagnostic markers like ALT (alanine transaminase), AST (aspartate aminotransferase), STB (serum total bilirubin), CB (conjugated bilirubin), UCB (unconjugated bilirubin), and HBV-DNA. Participants, who have hepatitis $B$ history or HBsAg positive history for more than six months, were diagnosed as chronic HBV infection if they were positive to HBsAg and/or HBV-DNA. We used both western and Chinese medicine criteria to divide $\mathrm{CHB}$ patients into two groups. First, participants were satisfied with the following requirements: (1) serum HBsAg positive for over 6 months; (2) HBV-DNA positive; (3) continuous or repeated elevated serum ALT in last 12 months; (4) being 18 60 years old; (5) no planed move during the test. Then, LSSD-CHB and DHSM$\mathrm{CHB}$ patients were diagnosed using the clinical symptoms mentioned before. CHB patients were diagnosed as LSSDCHB when they met the criteria: (1) Mi and Mii; (2) Mi, Sii, and Siii; (3) Mii and Si. DHSM-CHB patients were diagnosed as follows: (1) M1 and M2; (2) M1, S1, and S2; (3) M2 and two of the secondary symptoms. We also filtered the patients when they satisfied one of the following criteria: (1) being associated with other types of hepatitis viruses or human immunodeficiency virus (HIV); (2) cirrhosis, malignancy; (3) being diagnosed with fulminant hepatitis (including acute, subacute, and chronic severe hepatitis); (4) being associated with drug or toxic liver, autoimmune hepatitis, and genetic-metabolic liver disease; (5) heart, lung, kidney, endocrine, blood, and other serious diseases; (6) pregnant women and lactating women; (7) mental disorders, in line with Chinese Classification of Mental Disorders Diagnosis (CCMD-3) standard; (8) other individuals not suitable for the cohort study.

2.4. Protein Preparation. Serum sample $(200 \mu \mathrm{L})$ from each patient was processed to reduce the complexity by using 
ProteoMiner $^{\mathrm{TM}}$ Kits (Bio-Rad Laboratories, Hercules, CA, USA). Then, the sample was eluted using Lysis buffer at pH 8.5 (2M Thiourea, 7M Urea, 4\% CHAPS, and $40 \mathrm{mM}$ Tris- $\mathrm{HCl}$ ), reduced using $10 \mathrm{mM} \mathrm{DTT}$ at $56^{\circ} \mathrm{C}$ for $1 \mathrm{~h}$, and alkylated using $55 \mathrm{mM}$ IAM in darkness for $1 \mathrm{~h}$. After being precipitated within chilled acetone $(4 \times$ volume $)$ at $-20^{\circ} \mathrm{C}$ overnight, the protein sample was centrifuged at $30,000 \times \mathrm{g}$ for $15 \mathrm{~min}$ at $4^{\circ} \mathrm{C}$; the pellet was next dissolved in $500 \mu \mathrm{L}$ of $0.5 \mathrm{M}$ triethylammonium bicarbonate (Applied Biosystems, Milan, Italy) and sonicated at $200 \mathrm{~W}$ in ice for $15 \mathrm{~min}$. Finally, the samples were centrifuged again at $30,000 \times \mathrm{g}$ for $15 \mathrm{~min}$ at $4^{\circ} \mathrm{C}$, and the supernatant was quantified using Bradford Protein Assay Kit (CWBIO, Beijing, China) and stored at $-80^{\circ} \mathrm{C}$ for subsequent analysis.

2.5. iTRAQ Sample Labelling, SCX Fractionation, and LCESI-MS/MS Analysis. Proteins isolated from 10 individuals in the same group were pooled for iTRAQ labelling. Pooled protein samples $(100 \mu \mathrm{g})$ were digested using Trypsin Gold (Promega, Madison, WI, USA) at $37^{\circ} \mathrm{C}$ for $16 \mathrm{~h}$ (protein: trypsin $=30: 1$ ). Digested peptides were dried by vacuum centrifugation, reconstituted in $0.5 \mathrm{M}$ triethylammonium bicarbonate (Applied Biosystems, Milan, Italy), and processed 8plex iTRAQ (Applied Biosystems) labelling following the protocols. Samples were labelled with the iTRAQ tags as follows: LSSD-CHB (113, 115, and 117), DHSM-CHB (114, 116, and 118), and HCTL (119 and 121). After being incubated at room temperature for $2 \mathrm{~h}$, all the peptide mixtures were then pooled and dried by vacuum centrifugation. Strong cation exchange (SCX) chromatography was performed using the LC-20AB HPLC Pump system (Shimadzu, Kyoto, Japan), as previously described [18].

SFX fractions were resuspended in buffer A $(2 \% \mathrm{ACN}$, $0.1 \% \mathrm{FA})$, followed by a centrifugation at 20,000 $\mathrm{g}$ for $10 \mathrm{~min}$. Then, $10 \mu \mathrm{L}$ of the supernatant was loaded onto a $2 \mathrm{~cm} \mathrm{C18}$ trap column on a LC-20AD nanoHPLC (Shimadzu, Kyoto, Japan) by the autosampler and eluted onto a $10 \mathrm{~cm}$ analytical C18 column (inner diameter $75 \mu \mathrm{m}$ ) packed in-house. At $300 \mathrm{~nL} / \mathrm{min}$ the samples were loaded with buffer B $(98 \%$ $\mathrm{ACN}, 0.1 \% \mathrm{FA}$ ) as the following procedural: $5 \% \mathrm{~B}$ for $1 \mathrm{~min}$, a 44 min gradient from 2 to $35 \% \mathrm{~B}$, a 2 min linear gradient to $80 \%$, and $80 \%$ B for $4 \mathrm{~min}$. Finally, the chromatographic conditions were restored in $1 \mathrm{~min}$. Data acquisition was performed with an Q EXACTIVE (Thermo Fisher Scientific, San Jose, CA) coupled online to the HPLC, as described $[19,20]$.

2.6. Database Search and Protein Quantification. Database search and protein quantification were performed using Mascot (Matrix Science, London, UK; version 2.4.0). Briefly, raw data files acquired from the Orbitrap were converted into mascot generic format (MGF) files using msconvert tool of ProteoWizard (http://proteowizard.sourceforge.net/) [21]. To identify expressed proteins and quantify them, all $20 \mathrm{MGF}$ files were merged and searched against UniProtHUMAN (2016_04, 152,544 sequences) database using Mascot with parameters: quantification: iTRAQ 8plex (Applied Biosystems iTRQA ${ }^{\mathrm{TM}}$ 8-plex); enzyme: trypsin; fixed modification: carboxymethyl (C), iTRAQ8plex (N-term) and iTRAQ8plex $(\mathrm{K})$; variable modifications: dioxidation $(\mathrm{M})$, oxidation $(\mathrm{M})$, and iTRAQ8plex (Y), mass values: monoisotopic; peptide mass tolerance: \pm 15 ppm; fragment mass tolerance: $\pm 20 \mathrm{mmu}$; max missed cleavages: (1) The charge states of peptides were set to +2 and +3 . Specifically, an automatic decoy database search was performed in Mascot by choosing the decoy checkbox in which a random sequence of database is generated and tested for raw spectra as well as the real database. To reduce the probability of false peptide identification, only peptides at the $95 \%$ confidence interval by a Mascot probability analysis greater than "identity" were counted as identified. And each confident protein identification involves at least one unique peptide.

2.7. Protein Different Expression and Functional Analysis. To identify differentially expressed proteins in LSSD-CHB and DHSM-CHB compared to HCTL, we set a cut-off for fold change $(>1.2)$ of protein abundance provided by Mascot and $p$ value $(<0.05)$ calculated by edgeR [22]. Venn diagram of upand downregulated proteins was analyzed by InteractiVenn (http://www.interactivenn.net/) [23]. To annotate potential functions of proteins, UniProt IDs of candidate proteins were submitted to DAVID Bioinformatics Resources 6.7 (https://david.ncifcrf.gov/home.jsp) [24] and STRING v10 (http://string-db.org/) [25], Gene Ontology (GO), and KEGG pathway were selected, and we used false discovery rate (FDR) to control the results. Protein-protein interaction networks were analyzed by STRING.

2.8. Western Blot Analysis. Protein samples obtained from serum of 9 LSSD-CHB patients, 9 DHSM-CHB patients, and 6 healthy individuals were resolved by 12\% SDS-PAGE using Miniprotean II electrophoresis unit (Bio-Rad) run at constant $120 \mathrm{~V}$ for $1 \mathrm{~h}$ and transferred to a PVDF membrane (Amersham Biosciences) under a constant voltage of $15 \mathrm{~V}$ for $20 \mathrm{~min}$. The membranes were blocked with 5\% skim milk powder in Tris-buffered saline with $0.05 \%$ Tween-20 (TTBS) for $1 \mathrm{~h}$ and probed in TTBS with primary antibodies (1:500, Santa Cruz Biotechnology, CA, USA), antiPSMA7 (sc-166761), anti-PF4V (sc-367359), anti-PSMA6 (sc271187), anti-SERPING1 (sc-377062), anti-ACTB (sc-8432), anti-AHSG (sc-137102), anti-CTSC (sc-74590), anti-PLTP (sc-271596), and anti-ALB (sc-46293), followed by incubation with secondary antibody $(1: 1000)$ for $1 \mathrm{~h}$ in darkness. All antibody incubations were carried out using gentle orbital shaking at room temperature. Western blots were washed five times in TTBS $(5 \mathrm{~min} \times 2$ and $10 \mathrm{~min} \times 3)$ after each incubation step and visualized with enhanced chemiluminescence (ECL, GE Healthcare) following the manufacturers' instructions. Band intensities on the Western blots were quantified using ImageJ (Wayne Rasband, National Institutes of Health). Albumin was used as reference to calculate the relative intensity of each protein. Then, mean \pm SD values of each protein in HCTL and patients were calculated and compared using GraphPad Prism (http://www.graphpad.com/).

2.9. Statistical Analysis. Statistical analysis including the calculation of mean value, standard deviation (SD), and students' $t$-test was performed by using GraphPad Prism (v 
TABLE 1: Clinical diagnosis of patients who participated in this study.

\begin{tabular}{|c|c|c|c|c|c|}
\hline Diagnosis & Unit & LSSD-CHB $(n=30)$ & DHSM-CHB $(n=30)$ & HCTL $(n=20)$ & $p$ value \\
\hline \multicolumn{6}{|l|}{ Sex } \\
\hline Male & & 24 & 15 & 10 & \\
\hline Female & & 6 & 15 & 10 & \\
\hline Age & & $17 \sim 56$ & $18 \sim 60$ & $24 \sim 56$ & \\
\hline Mean age & Years & 30.8 & 36.83 & 36.15 & \\
\hline Standard deviation (SD) & & 10.526 & 11.885 & 11.554 & \\
\hline \multicolumn{6}{|l|}{ Hepatitis B surface antigen (HBsAg) } \\
\hline Positive & & 28 & 29 & & \\
\hline Negative & & 0 & 0 & & \\
\hline \multicolumn{6}{|l|}{ Hepatitis surface antibody (anti-HBs) } \\
\hline Positive & & 2 & 0 & & \\
\hline Negative & & 25 & 29 & & \\
\hline \multicolumn{6}{|l|}{ Hepatitis Be antigen ( $\mathrm{HBeAg})$} \\
\hline Positive & & 21 & 19 & & \\
\hline Negative & & 7 & 9 & & \\
\hline \multicolumn{6}{|l|}{ Hepatitis Be antibody (anti-HBe) } \\
\hline Positive & & 9 & 12 & & \\
\hline Negative & & 19 & 16 & & \\
\hline \multicolumn{6}{|l|}{ Hepatitis B core antibody (anti-HBc) } \\
\hline Positive & & 28 & 29 & & \\
\hline Negative & & 0 & 0 & & \\
\hline Alanine transaminase $(A L T)$ & $\mathrm{IU} / \mathrm{L}$ & $13.8 \sim 627$ & $34 \sim 673$ & & 1.0 \\
\hline Mean ALT level & & 190.153 & 187.393 & & \\
\hline SD & & 161.231 & 177.618 & & \\
\hline Aspartate aminotransferase (AST) & $\mathrm{IU} / \mathrm{L}$ & $26.5 \sim 345$ & $28 \sim 556$ & & 0.9999 \\
\hline Mean AST & & 96.74 & 142.427 & & \\
\hline SD & & 71.699 & 153.539 & & \\
\hline Serum total bilirubin (STB) & umol/L & $10.1 \sim 48.63$ & $6.5 \sim 109.5$ & & 1.0 \\
\hline Mean STB & & 19.208 & 20.643 & & \\
\hline SD & & 8.926 & 18.127 & & \\
\hline Conjugated bilirubin (CB) & $\mathrm{umol} / \mathrm{L}$ & $2.4 \sim 16.4$ & $2.3 \sim 99.2$ & & 1.0 \\
\hline Mean CB & & 6.923 & 9.408 & & \\
\hline SD & & 3.542 & 17.208 & & \\
\hline Unconjugated bilirubin (UCB) & umol/L & $6 \sim 34.13$ & $3.3 \sim 29.3$ & & 1.0 \\
\hline Mean UCB & & 12.284 & 11.182 & & \\
\hline SD & & 5.951 & 4.921 & & \\
\hline$H B V-D N A$ & $\mathrm{IU} / \mathrm{mL}$ & $5.12 E+03 \sim 1.12 E+08$ & $6.34 E+04 \sim 9.40 E+08$ & & 0.0096 \\
\hline Mean HBV-DNA & & $2.521 E+07$ & $5.655 E+07$ & & \\
\hline SD & & $3.221 E+07$ & $1.717 E+08$ & & \\
\hline
\end{tabular}

6.02). The Holm-Sidak method was used to calculate the statistical significance of multiple clinical diagnostic values.

\section{Results}

3.1. Diagnosis of the Patients. To study serum protein biomarkers in LSSD and DHSM CHB patients, we obtained a total of 80 participants, including 30 LSSD-CHB, 30 DHSM$\mathrm{CHB}$ patients, and 20 healthy volunteers. As shown in Table 1 and Table S1 in Supplementary Material available online at http://dx.doi.org/10.1155/2016/3290260, mean ages of LSSDCHB, DHSM-CHB, and HCTL were $30,36.8$, and 35.5 years, respectively. Except missing information of three, all patients were positive to $\mathrm{HBsAg}$ and anti-HBc. There were two LSSD$\mathrm{CHB}$ patients positive to anti-HBs, and 9 LSSD-CHB and 12 DHSM-CHB patients positive to anti-HBe. HBV-DNA levels in the blood samples of LSSD-CHB and DHSM-CHB patients were ranged from $5.12 E+03 \sim 1.12 E+08 \mathrm{IU} / \mathrm{mL}$ and $6.34 E+04 \sim 9.40 E+08 \mathrm{IU} / \mathrm{mL}$, respectively. It is interesting that hepatitis B viral load (HBV-DNA copies) was significantly different $(p=0.0096)$ in LSSD-CHB and DHSM-CHB patients. Next, we examined ALT, AST, STB, CB, and UCB levels in the blood samples of $\mathrm{CHB}$ patients. Mean values of 


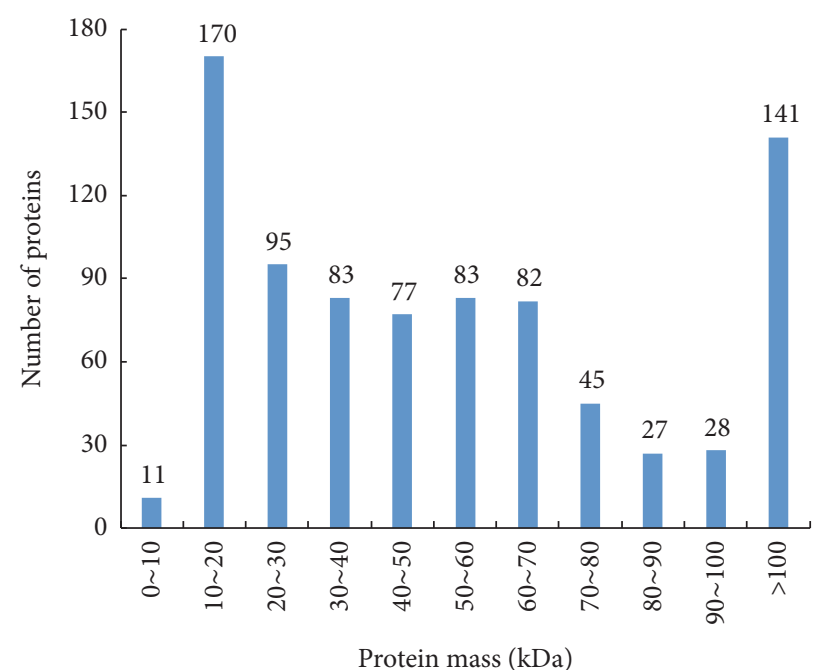

(a)

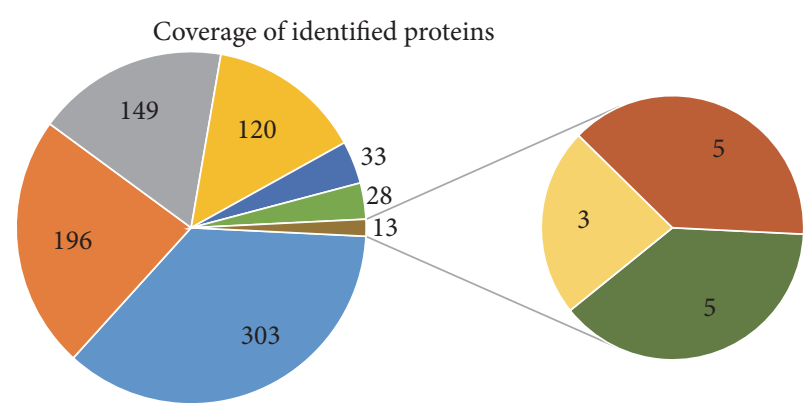

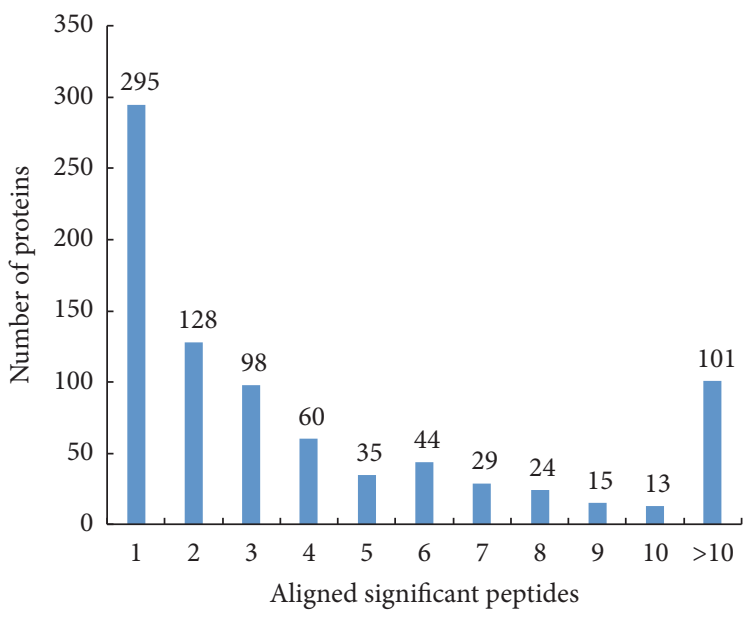

(b)

(c)

(d)

FIGURE 1: Identification and analysis of serum proteome of CHB infected patients. (a) Distribution of protein mass of identified proteins. (b) Number of peptides that match to proteins as indicated by MASCOT 2.4.0. (c) Coverage of identified proteins in CHB patient serum. (d) Correlation between samples calculated by corrplot.

these diagnosis biomarkers in the blood samples of LSSD$\mathrm{CHB}$ and DHSM-CHB patients were similar. In addition, the levels of ALT and AST remained at a high level, compared to healthy individuals $[26,27]$, which confirmed their $\mathrm{CHB}$ infection.

3.2. Protein Identification and Quantification by iTRAQ. Next, we quantified the serum proteins in these LSSD-CHB and DHSM-CHB patients using iTRAQ. Initially, a total of 371,034 spectra were generated by liquid chromatography coupled to mass spectrometry (LC-MS/MS) analysis. Of them, 98,243 spectra (5,591 unique peptides) were aligned to 842 proteins from 666 families. The mass distribution of identified proteins (Figure 1(a)) suggested by Mascot revealed $170(98.69 \%)$ were above $10 \mathrm{kDa}$, of which $170(20.19 \%)$ and $141(16.75 \%)$ were 10 to $20 \mathrm{kDa}$ and above $100 \mathrm{kDa}$, respectively. We also counted the proteins aligned with significant peptides, shown in Figure 1(b), and 547 (64.96\%) proteins were aligned by two and more peptides. In addition, the distribution of protein sequence coverage is shown in Figure 1(c). Protein sequence coverage with 40 100\%, 30 $40 \%, 20 \sim 30 \%, 10 \sim 20 \%$, and under $10 \%$ variation accounted for $8.79 \%, 14.25 \%, 17.70 \%, 23.28 \%$, and $35.99 \%$, respectively. In Figure 1(d), we showed correlation between two samples and found LSSD-CHB samples were closer to DHSM-CHB samples than HCTL.

3.3. Identification of Differentially Expressed Proteins. Differentially expressed proteins were defined as those showed greater than 1.2-fold change in relative abundance and a $p$ value $<0.05$. Compared to HCTL we identified a total of 392 proteins differentially expressed (Table S2), of which 273 were identified in LSSD-CHB group and 345 in DHSM$\mathrm{CHB}$ group. As shown in the volcano plots, we identified 172 


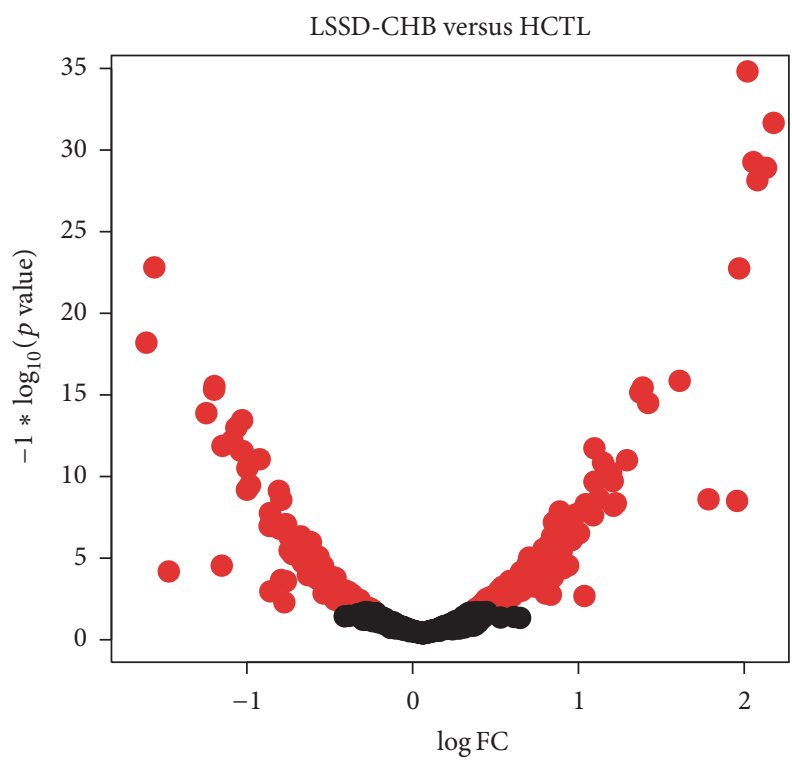

(a)

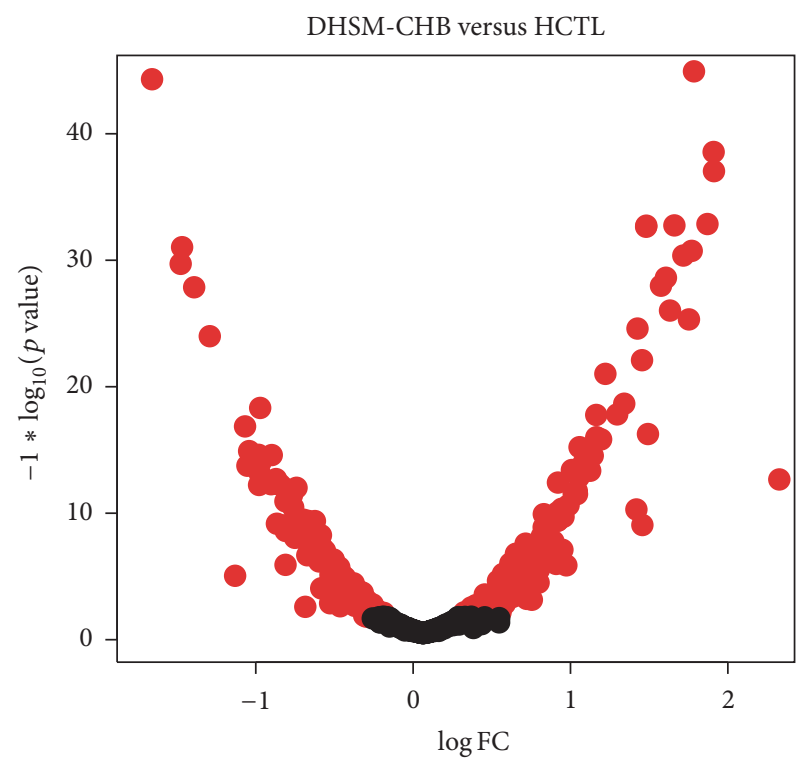

(b)

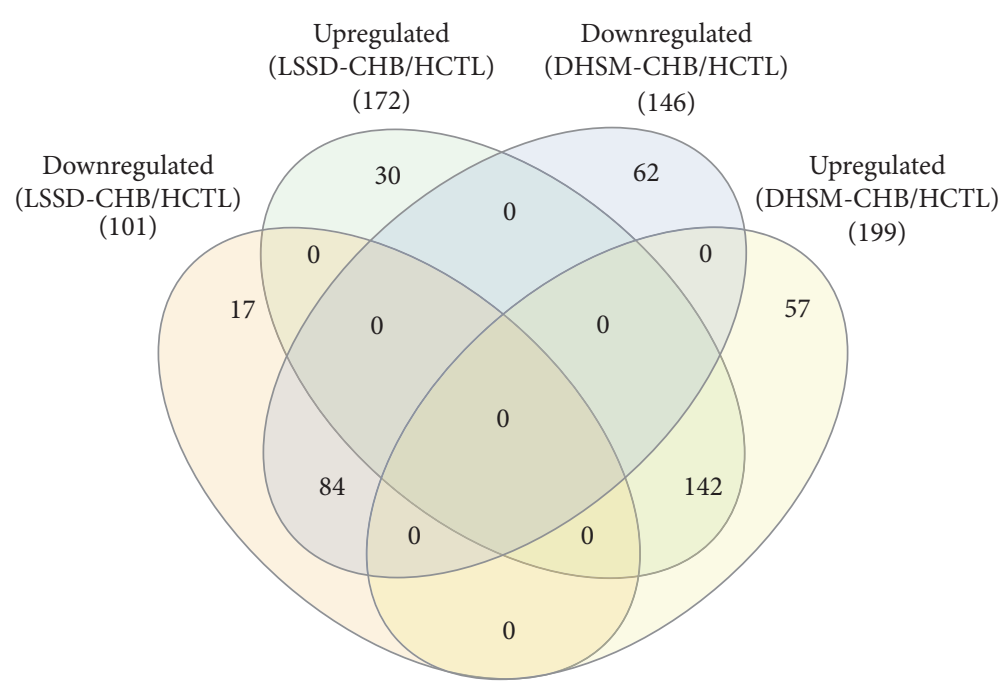

(c)

FIGURE 2: Identification of differentially expressed proteins in LSSD-CHB and DHSM-CHB patients compared with HCTL. (a) Volcano plot of differentially expressed proteins between LSSD-CHB and HCTL groups. (b) Volcano plot of differentially expressed proteins between DHSM-CHB and HCTL groups. (c) Venn diagram of up- and downregulated proteins in LSSD-CHB and DHSM-CHB groups.

upregulated and 101 downregulated proteins in LSSD-CHB group (Figure 2(a)) and 199 upregulated and 146 downregulated proteins in DHSM-CHB group (Figure 2(b)), compared to HCTL group. Venn diagram (Figure 2(c)) revealed LSSD-CHB and DHSM-CHB shared 142 upregulated and 84 downregulated proteins; 30 and 57 proteins were exclusively upregulated in LSSD-CHB and DHSM-CHB, respectively; 17 and 62 proteins were exclusively downregulated in LSSD$\mathrm{CHB}$ and DHSM-CHB, respectively; and no protein was identified with upregulation in one $\mathrm{CHB}$ subtype but with downregulation in another.

3.4. Potential Biomarkers for CHB. The identification of proteins differentially expressed in LSSD-CHB and DHSM$\mathrm{CHB}$ groups relative to the HCTL group was of interest as these could provide leads for potentially useful diagnostic and prognostic biomarkers. First, we examined those 142 commonly upregulated and 84 commonly downregulated proteins. As shown in Table 2, the largest upregulated protein family was immunoglobulin related protein, showing 20 upregulated and 3 downregulated proteins identified. In clinical immunology, levels of immunoglobulins especially IgG can be used to characterize viral hepatitis in patients $[28,29]$. Four IgG subclasses (IgG1 to IgG4) differ in their heavy chain constant regions and have different effects on virus-cell fusion inhibition, virus neutralization, and overall course of infection, as have been reported for various viruses including HIV [30] and HBV [31]. Highly expressed proteins encoding heavy chains for immunoglobulins including IGHG1, IGHG3, IGHG4, and IGH@ have been reported 


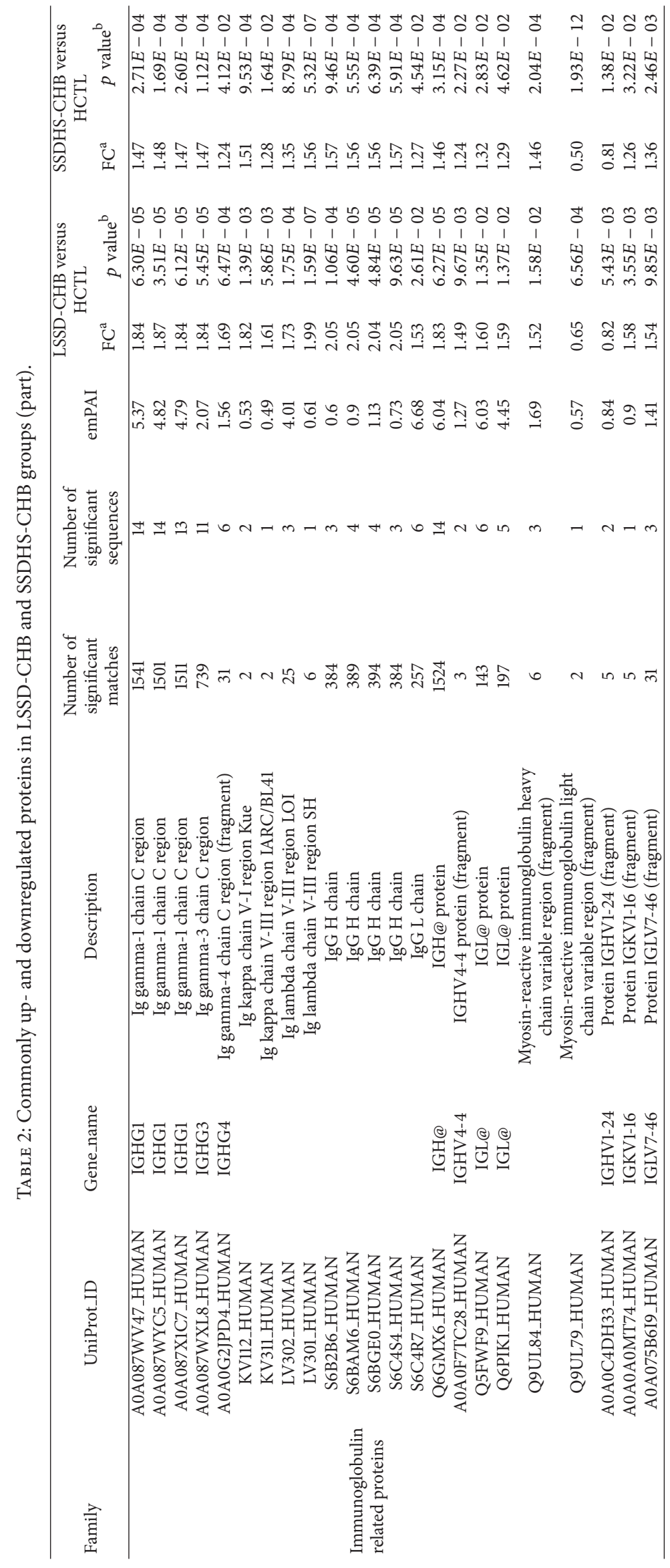




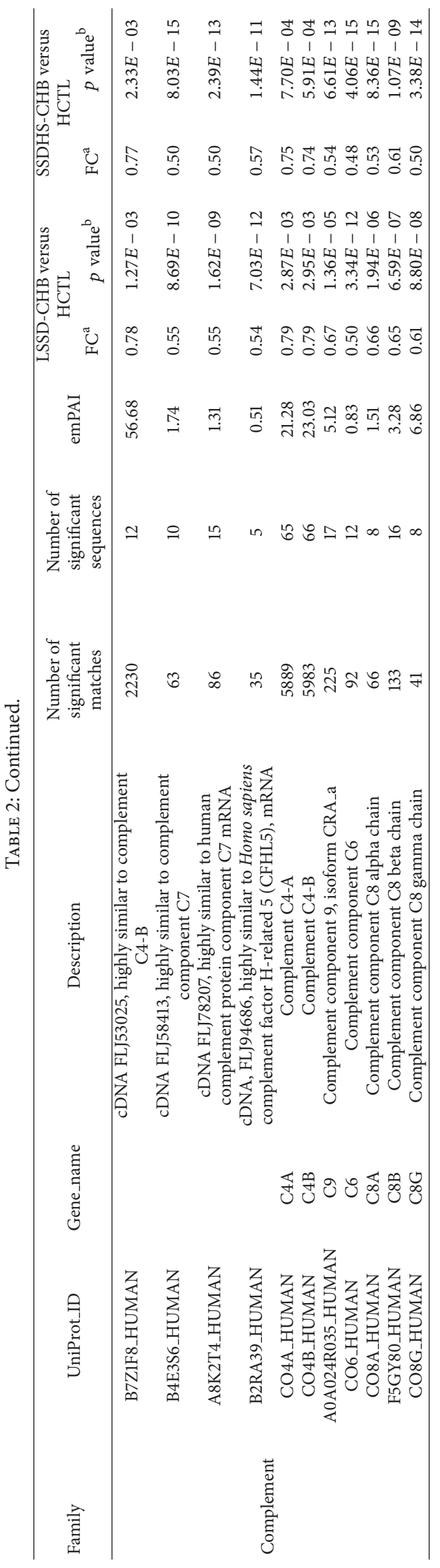




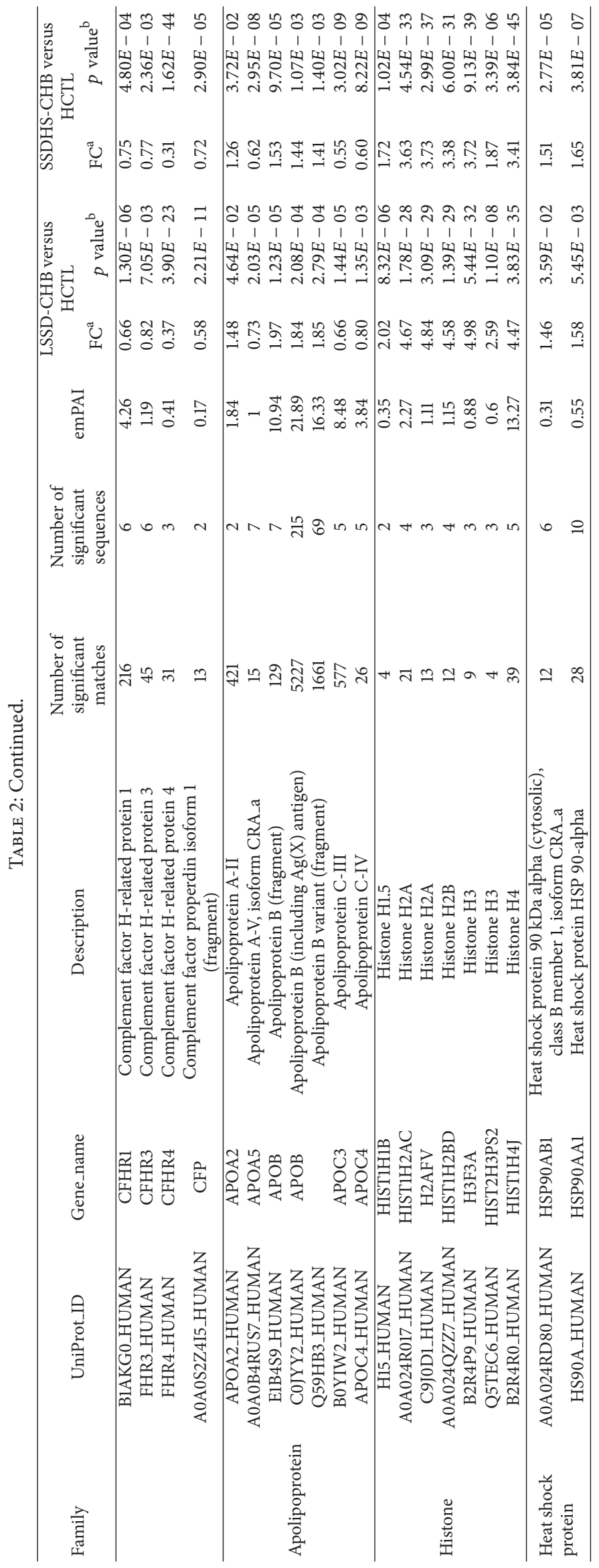




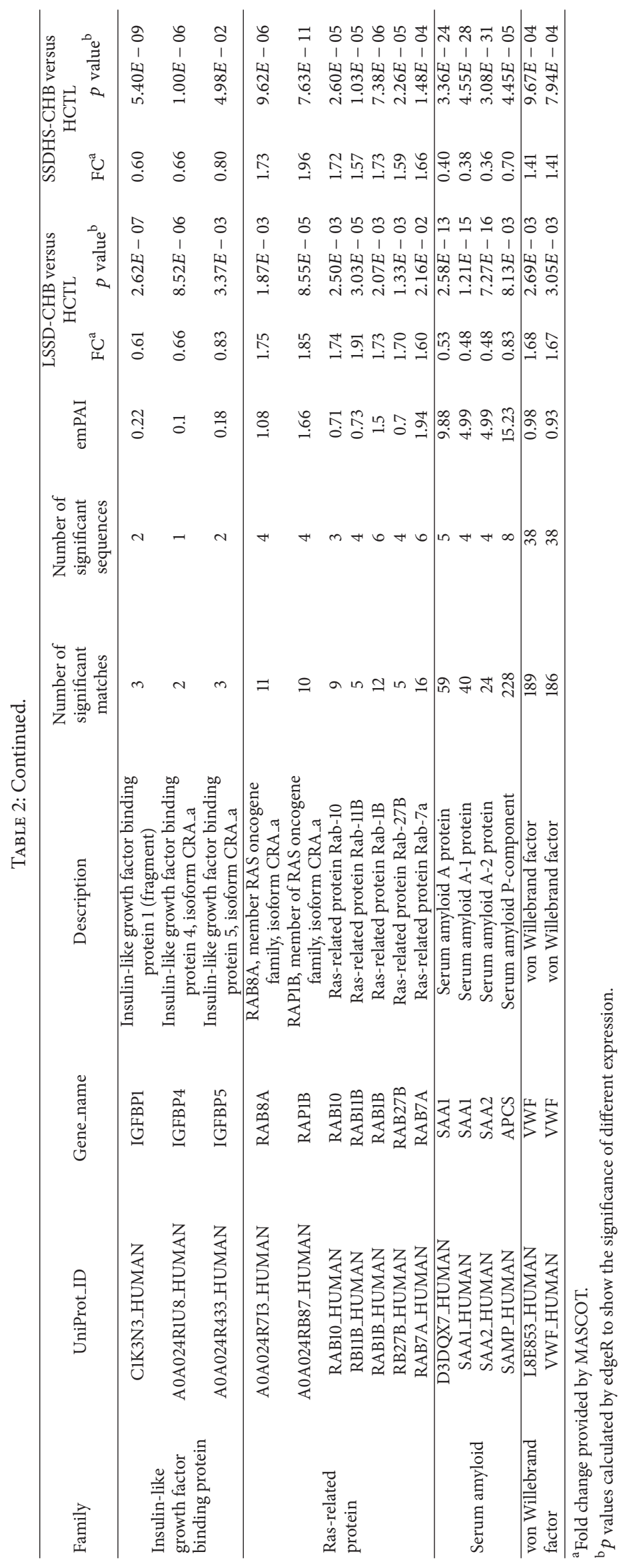




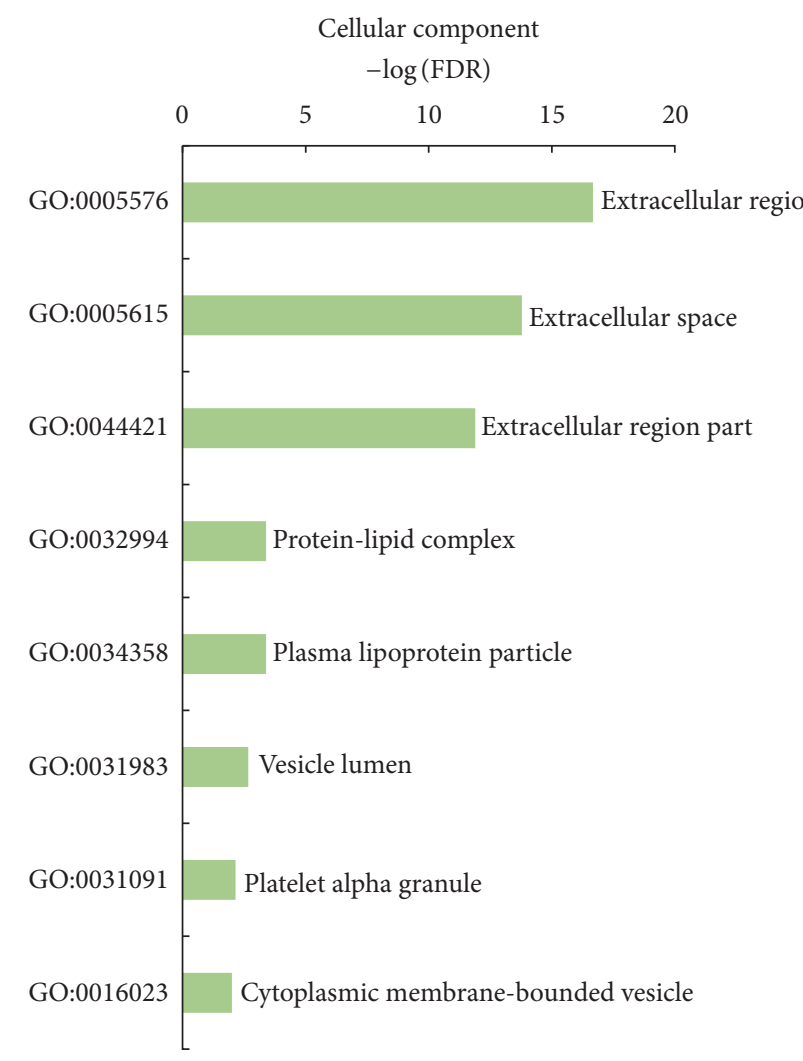

(a)

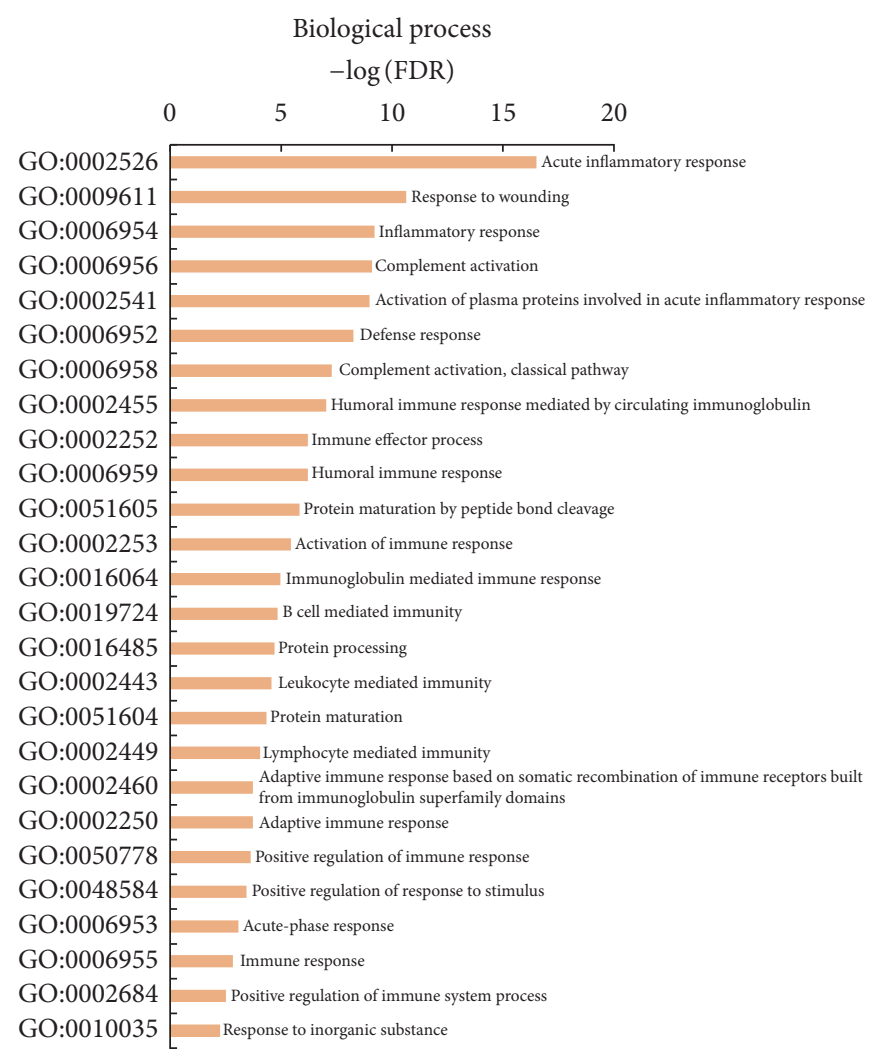

(b)

FIGURE 3: Gene Ontology annotation for shared differentially expressed proteins in LSSD- and DHSM-CHB groups: (a) cellular component, (b) biological process.

with upregulation in HBV [32, 33] and HCC patients [34]. Other upregulated protein families such as heat shock protein, histone, ras-related protein, and von Willebrand factor identified in current study have also been reported in patients infected by HBV or hepatitis C virus (HCV) [35-38]. The largest downregulated protein family was complement, 15 complement proteins downregulated in LSSD-CHB with 0.82 - to 0.37 -fold change and in DHSM-CHB with 0.77to 0.31 -fold change. Other protein families like insulin-like growth factor binding protein and serum amyloid protein were also decreased in CHB patients in comparison to HCTL group. In addition, several known upregulated proteins from other families in patients infected by HBV or HCV (Table 2), such as apolipoproteins (APOA2, APOB, and APOB-variant) [39, 40], A2M (alpha-2-macroglobulin) [41], alpha-actinin-3 (ACTN3) [42, 43], vimentin (VIM) [38], and putative uncharacterized proteins (DKFZp686N02209 and DKFZp686I04196) [34, 44, 45], were identified in LSSD$\mathrm{CHB}$ and DHSM-CHB groups. The different expression of proteins in the serum of $\mathrm{CHB}$ patients indicates they may have functions in response of $\mathrm{HBV}$ and $\mathrm{CHB}$ processing and can be used as biomarkers in clinical diagnosis.

We next analyzed the potential functions of commonly differentially expressed serum proteins in LSSD-CHB and DHSM-CHB groups using DAVID Bioinformatics Resources 6.7 [24] and STRING v10 [25]. Cellular component annotation
(Figure 3(a)) showed 63 and 7 proteins were "extracellular region" (GO: 0005576, GO: 0005615, and GO: 0044421) and "lipids" (GO: 0032994 and GO: 0034358), respectively. However biological process annotation (Figure 3(b)) showed most of the differentially expressed proteins associated with immune response, including "acute inflammatory response" (GO: 0002526), "response to wounding" (GO: 0009611), “inflammatory response” (GO: 0006954), "complement activation" (GO: 0006956), "defense response" (GO: 0006952), "humoral immune response mediated by circulating immunoglobulin" (GO: 0002455), "immune effector process" (GO: 0002252), "B cell mediated immunity" (GO: 0019724), and "activation of immune response" (GO: 0002253). It has been well studied that immunological events are necessary to control hepatitis B virus (HBV) infection $[46,47]$. In addition, KEGG pathway analysis also showed differentially expression proteins function mainly in the pathways of "complement and coagulation cascades" (hsa04610), "systemic lupus erythematosus" (hsa05322), "focal adhesion" (hsa04510), and "viral carcinogenesis" (hsa05203). Overall, differentially expressed proteins in both LSSD-CHB and DHSM-CHB groups have potential ability to be used as biomarkers.

3.5. Dysregulated Proteins Detected Exclusively in LSSD$\mathrm{CHB}$ and DHSM-CHB. Next, we examined differentially 
expressed proteins exclusively in LSSD-CHB and DHSM$\mathrm{CHB}$ groups. A total of 30 upregulated and 17 downregulated proteins were specifically identified in LSSD-CHB patient serum samples (Table 3). Among them 11 upregulated immunoglobulin related proteins, gelsolin (GSN), serum paraoxonase/lactonase 3 (PON3), likely SNC73 protein, transient receptor potential cation channel subfamily $M$ member 8 (TRPM8), and several uncharacterized proteins (DKFZp686M08189, DKFZp686C02220, and DKFZp686K04218) attracted our attention due to their high abundance. Serum PON3 concentrations have been reported to increase in patients with $\mathrm{CHB}$ or cirrhosis and showed significant direct correlations with the degree of periportal abnormalities including fibrosis and with serum FAS (a marker of antiapoptosis) concentrations [48]; however, serum gelsolin level has been reported to reduce significantly in patients with acute liver failure (47\%), myocardial infarction (69\%), sepsis (51\%), and myonecrosis (66\%) [49]. Among the specifically downregulated serum proteins in LSSD-CHB patients fibulin-1 (FBLN1) is a tumor suppressor in hepatocellular carcinoma [50]. Proteins specifically differentially expressed in LSSD-CHB patients were predicted to function mainly in biological processes of "protein activation cascade" (GO: 0072376), "regulation of response to wounding” (GO: 1903034), "blood coagulation, fibrin clot formation" (GO: 0072378), "negative regulation of response to stimulus" (GO: 0048585), and "acute-phase response" (GO: 0006953).

We also identified 57 upregulated and 62 downregulated proteins exclusively in DHSM-CHB patients (Table 4). Two IGL@ proteins (Q6GMX4_HUMAN and Q6PIQ7_HUMAN) were specifically upregulated in DHSM-CHB patients with 1.27-fold change. Transthyretin (TTR), upregulated 1.34-fold in DHSM-CHB, can be induced by hepatitis $\mathrm{C}$ virus and activate TGF- $\beta$ signaling pathway with furin [51]. Interestingly, we found three members of tubulin (TUBA4A, TUBB1, and TUBB8) were upregulated only in DHSM-CHB patients compared with HCTL. Although there are few reports about tubulin and $\mathrm{HBV}$, it is well known that $42 \mathrm{kDa}$ tubulin alpha- 6 chain fragment in well-differentiated hepatocellular carcinoma tissues is from patients infected with HCV [52]. In addition, we found actinin, alpha 1 (ACTN1), which can directly interact with HCV [53], GAPDH, which can bind to the HBV posttranscriptional regulatory element [54], and polymeric immunoglobulin receptor (PIGR), the main transporter of IgA [55], were upregulated in DHSM-CHB but not in LSSD-CHB. Among DHSM-CHB specifically downregulated proteins we identified three members of keratin type I (KRT9, KRT10, and KRT14) and another three members of keratin type II (KRT1, KRT2, and KRT6B). Although there is no evidence showing relation between these six keratin proteins with $\mathrm{CHB}$ or other liver diseases, variant keratins are associated with progression of fibrosis during chronic hepatitis $C$ infection [56]. Differentially expressed proteins exclusively detected in DHSM-CHB patients were predicted to be involved in the biological processes of "immune system process" (GO: 0002376), “response to stress” (GO: 0006950), "defense response" (GO: 0006952), "immune response” (GO:
0006955), and "single-organism metabolic process" (GO: 0044710).

Compared to HCTL group up- and downregulated proteins exclusively in LSSD-CHB and DHSM-CHB patients showed their potential ability of being biomarkers for these two subtypes of HBV induced CHB. Some of them have been reported in other studies; however, more experiments need to be performed to investigate their functions and validate their specificity and accuracy in clinical trials.

3.6. Validation of the Quantitative Proteomic Analysis. To validate the results obtained by proteomics analysis, eight randomly selected proteins and internal control albumin with altered expression profile were monitored by western blotting in an independent group of samples. Figures 4(a) and 4(b) showed the western blots for eight proteins and internal control albumin. PSMA6 (20S proteasome alpha6), PSMA7 (20S proteasome alpha7/alpha8) were upregulated and $\mathrm{PF} 4 \mathrm{~V}$ (platelet factor 4 variant) was downregulated in LSSD-CHB group compared to HCTL (Figure 4(c)). Except SERPING1 (plasma protease C1 inhibitor), AHSG (fetuin-A), ACTB (actin), CTSC (cathepsin C), and PLTP (phospholipid transfer protein) were upregulated in the serum of DHSM$\mathrm{CHB}$ patients (Figure $4(\mathrm{~d})$ ). Although the difference between patients and healthy participants was not significant by western blotting analysis, their regulations in patients and healthy group were consistent with iTRAQ. The original images of western blots (see Figure S1) might contain some differences due to brightness and contrast settings.

\section{Discussion}

Quantitation of serum or plasma proteins using comparative proteomics has recently been suggested as a suitable approach for the detection of liver disease biomarkers [17, 57-59]. The iTRAQ technology has been proposed as a powerful alternative to common tools (e.g., ELISA) and a flurry of applications emerged in the literature.

In this study, iTRAQ LC-MS/MS proteomics was used to detect serum protein as biomarkers of LSSD-CHB and DHSM-CHB patients. We compared the proteomics profile of LSSD-CHB and DHSM-CHB patients with healthy individuals and indicated 142 upregulated and 84 downregulated proteins shared by these two CHB subtype diseases. Protein-protein interaction network (Figure 5) showed several significant proteins might function in response to $\mathrm{HBV}$, such as actins (ACTA2, ACTB, ACTBL2, ACTN3, and ACTN4), apolipoproteins (APOA2, APOA5, APOB, APOC3, and APOC4), heat shock proteins (HSP90AA1 and HSP90AB1), and proteasome subunit proteins (PSMA1 and PSMA4). It has been reported that HBV core proteins can interact with the $\mathrm{C}$-terminal region of actin-binding protein [60] and HBV X protein ( $\mathrm{HBx})$ can block filamentous actin bundles by interaction with eEF1A1 (eukaryotic translation elongation factor 1 alpha 1) [61]. In addition, ACTA2 is a marker of hepatitis stellate cells and correlated significantly with necroinflammatory grades and fibrotic stages in $\mathrm{CHB}$ or CHC [13]. Apolipoproteins are supposed to enhance the infectivity of hepatitis virus during the infection $[39,62]$ and 


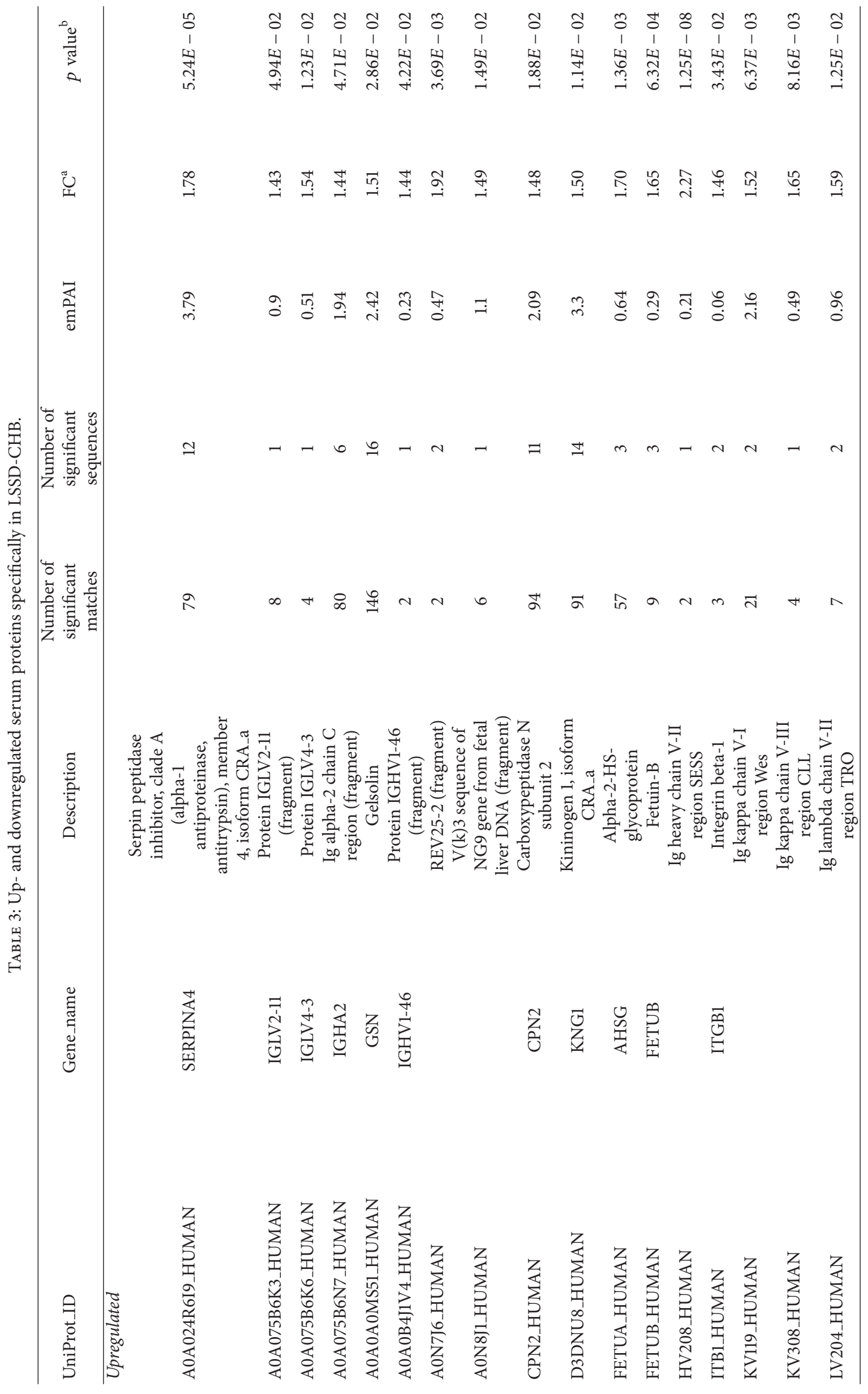




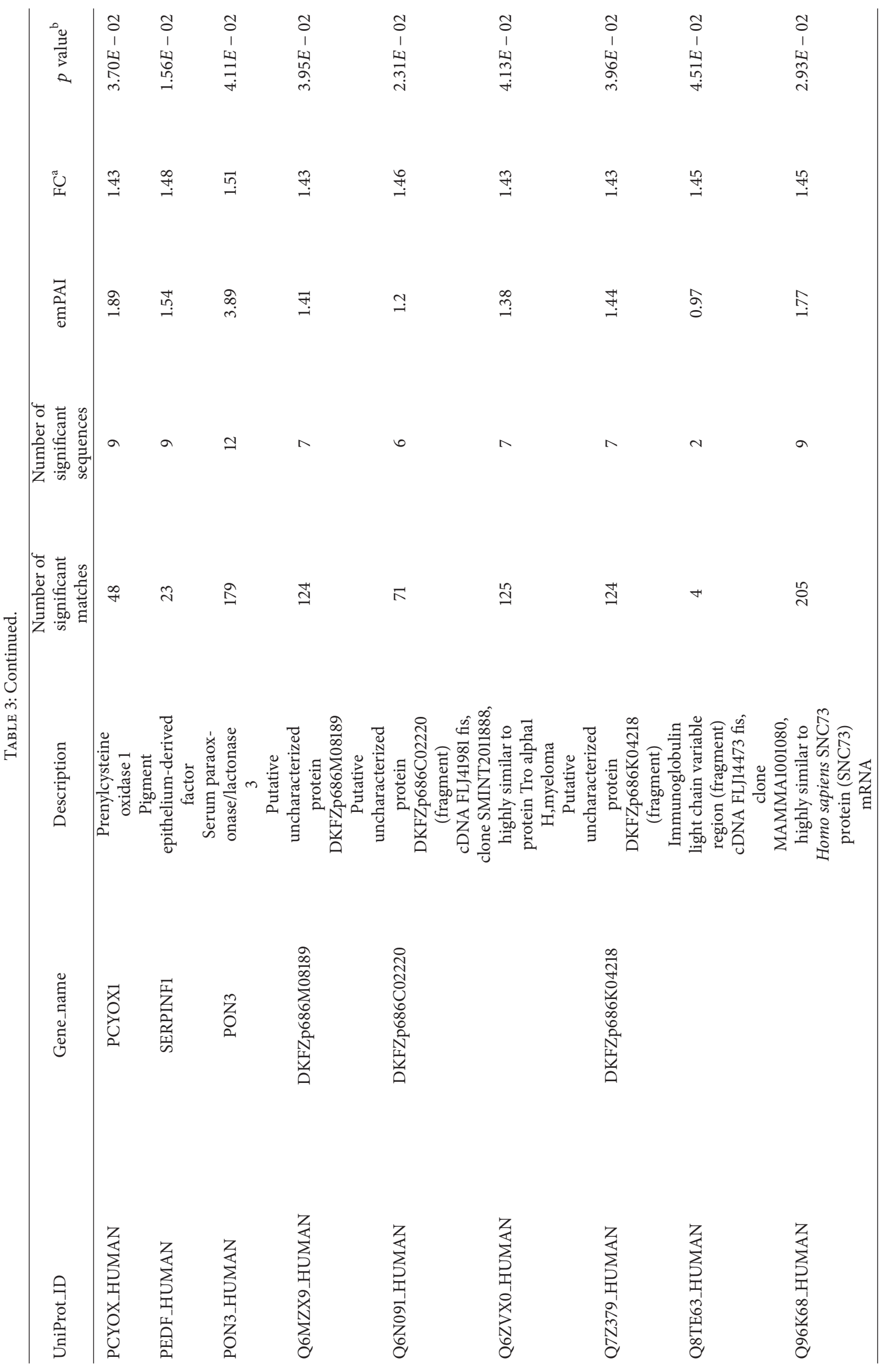




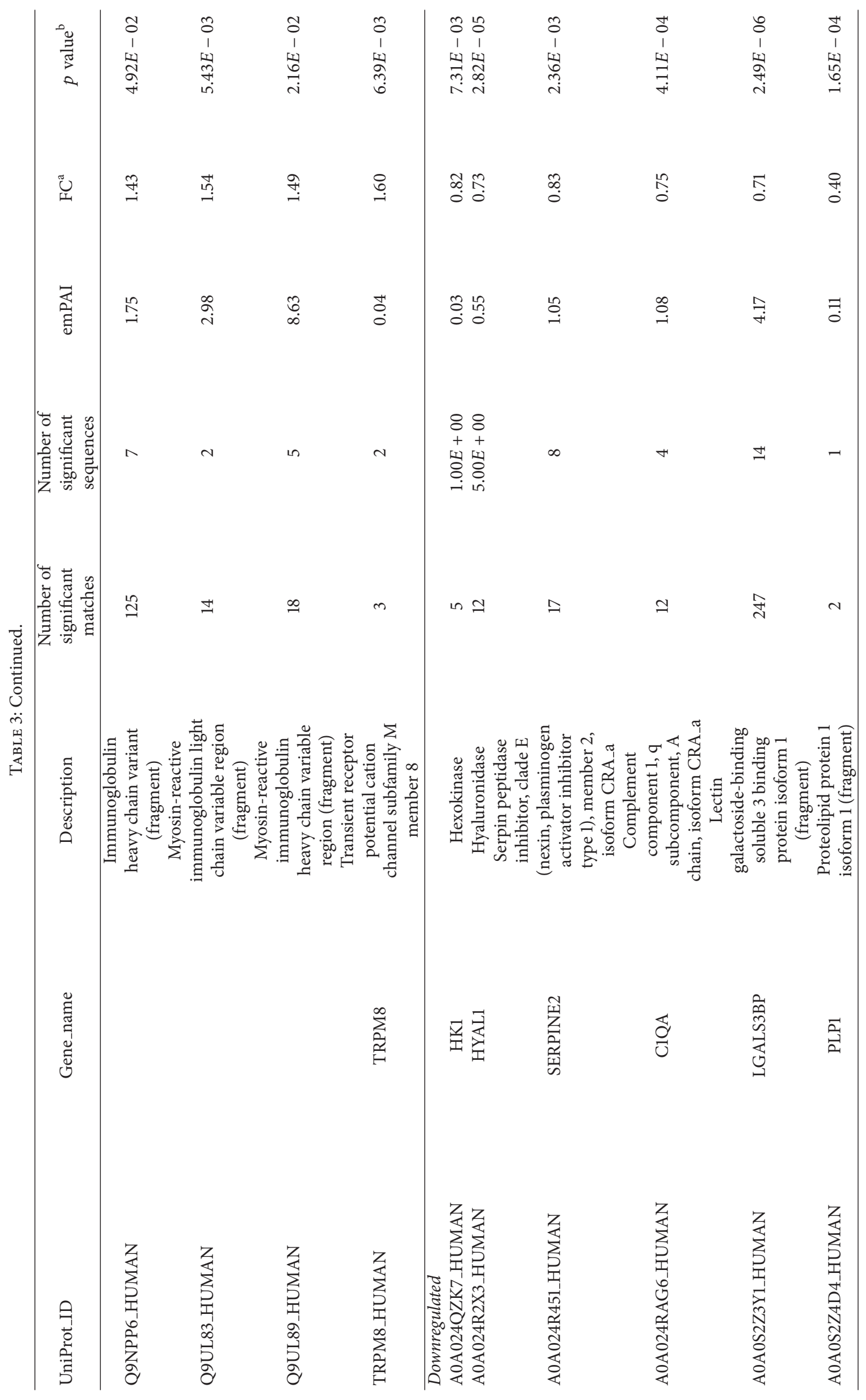




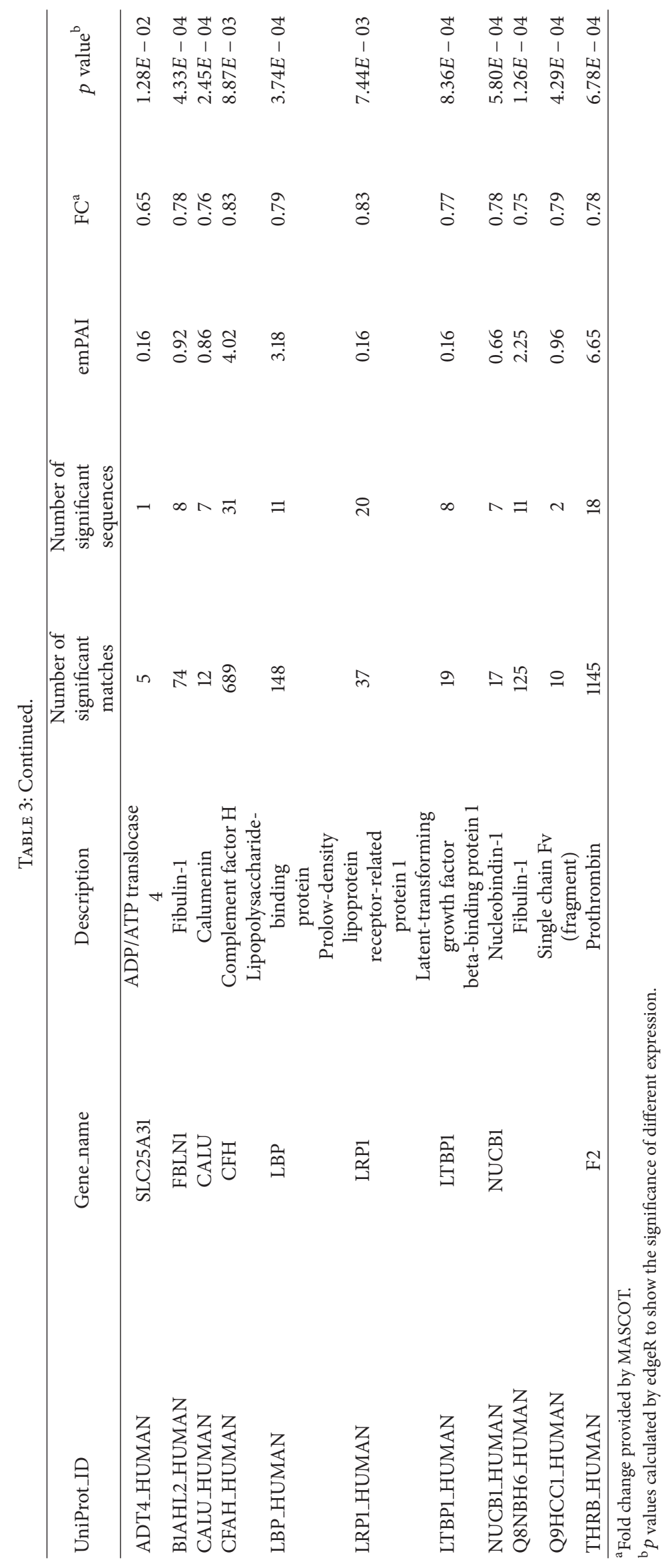




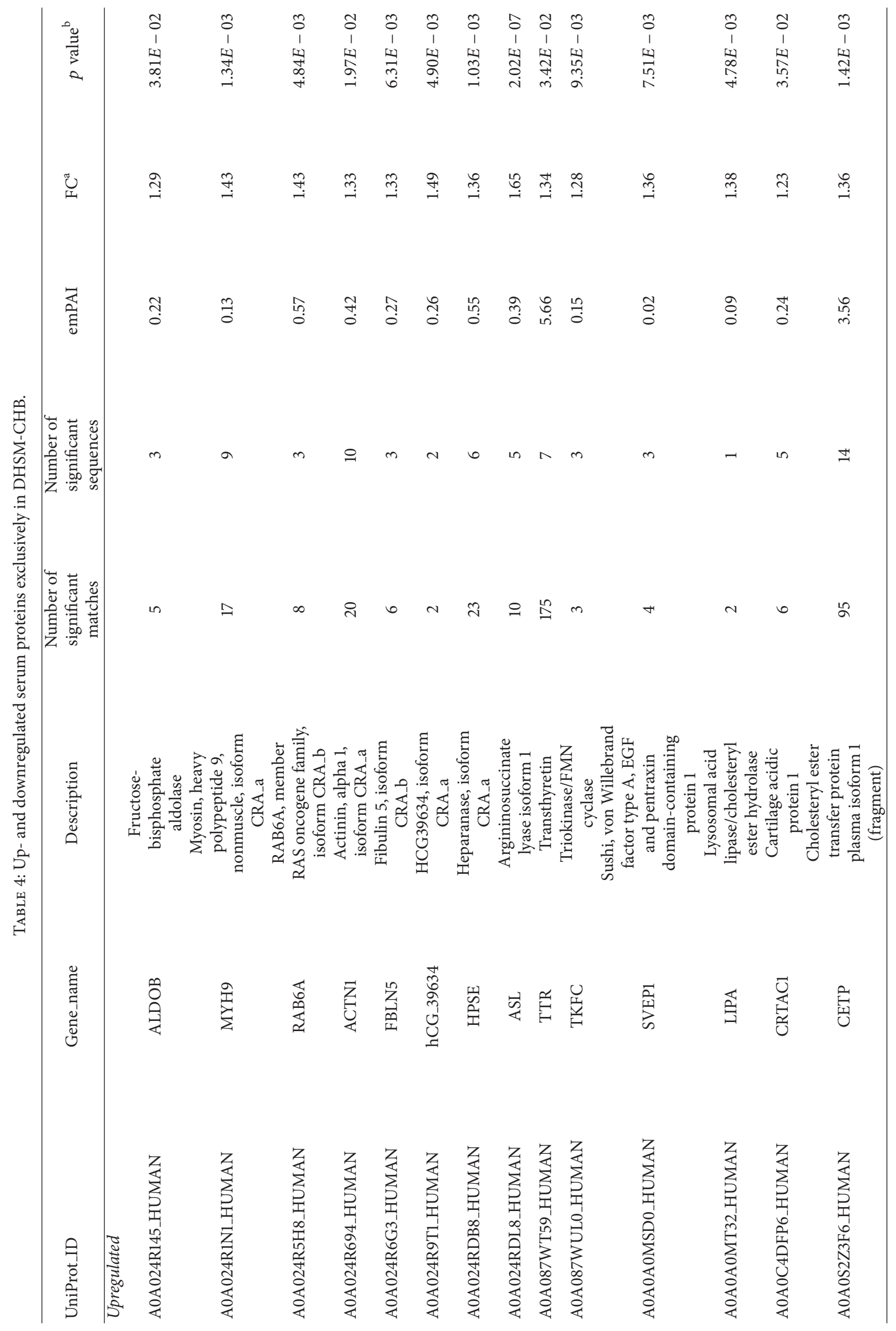




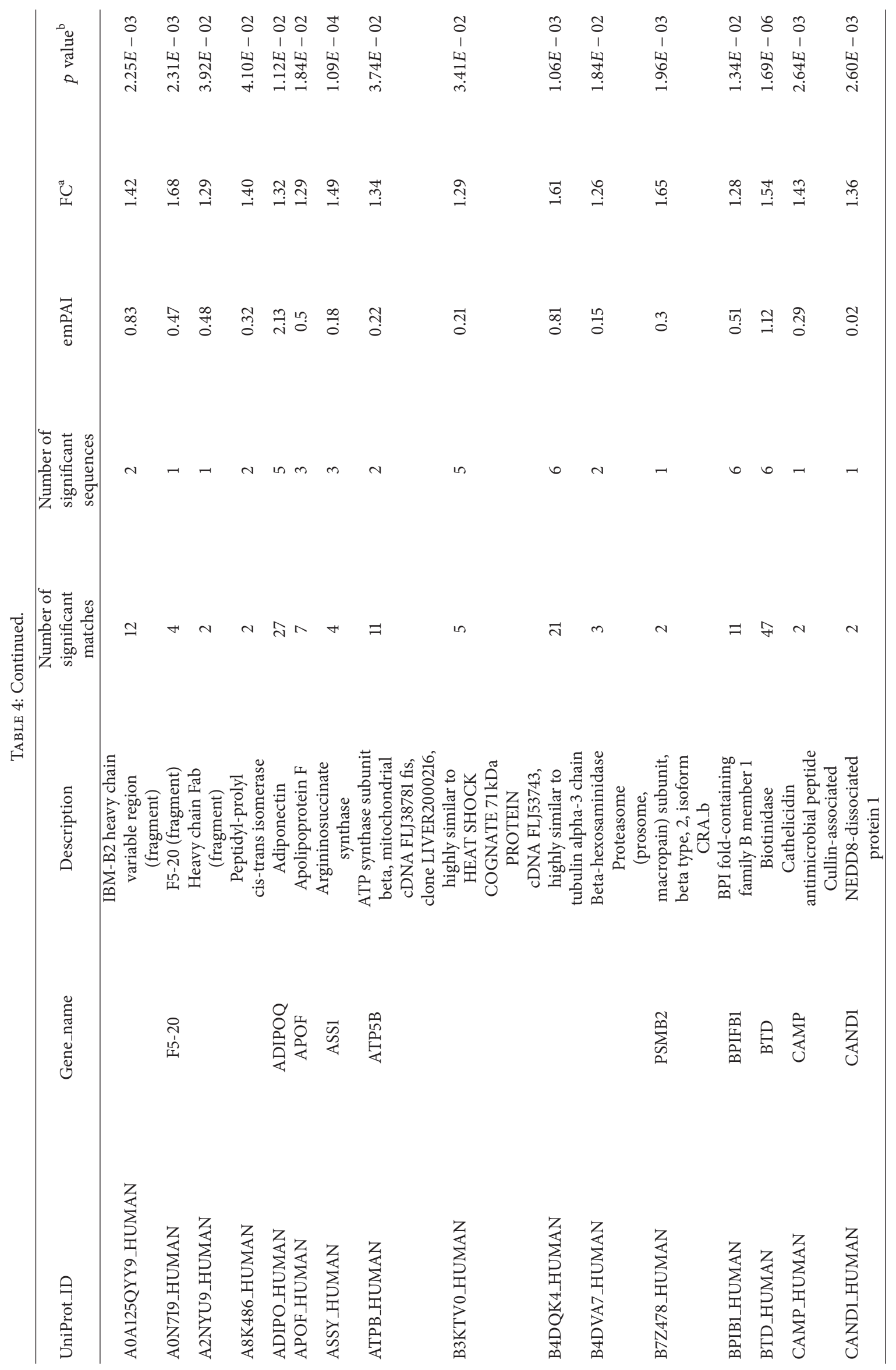




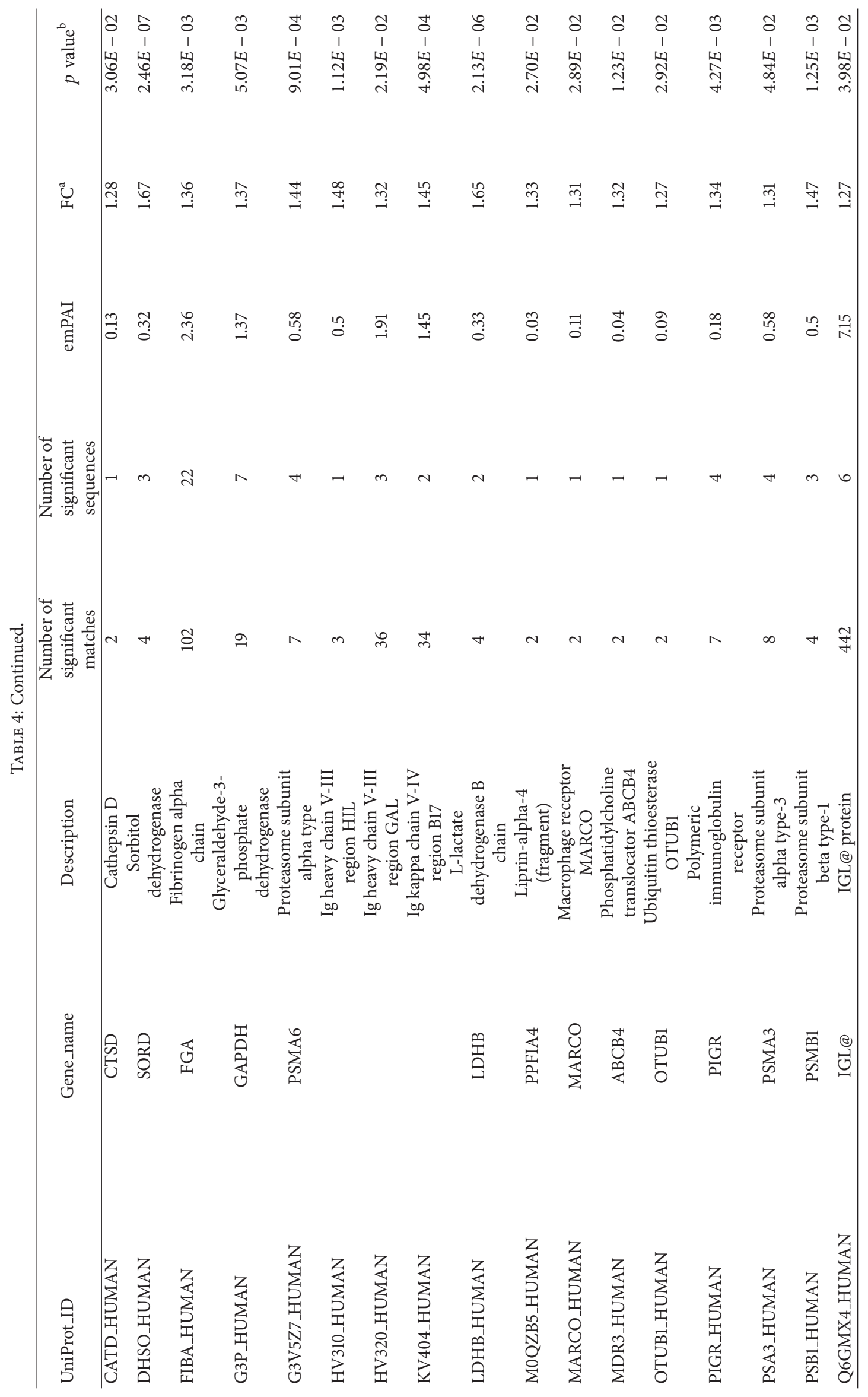




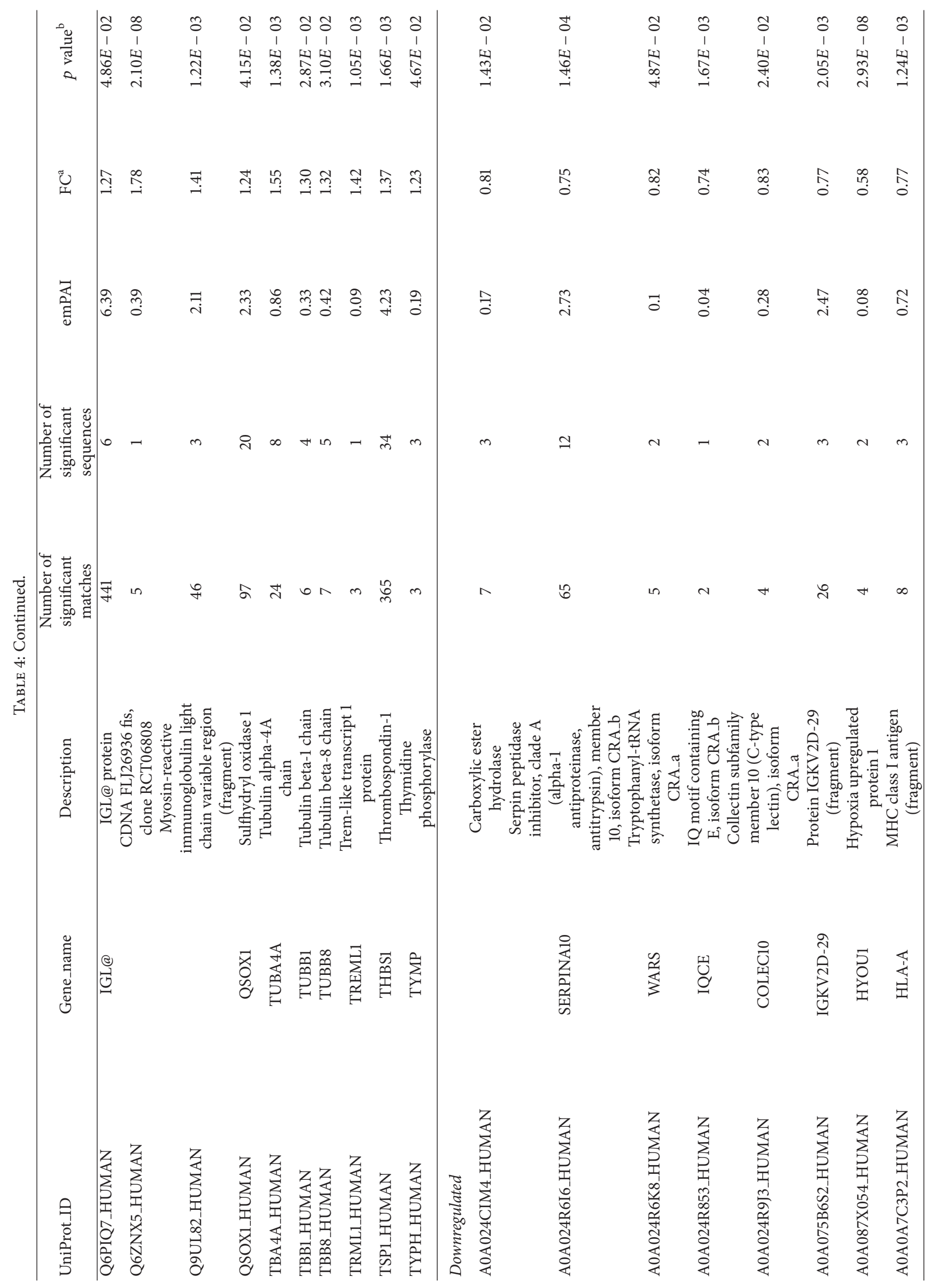




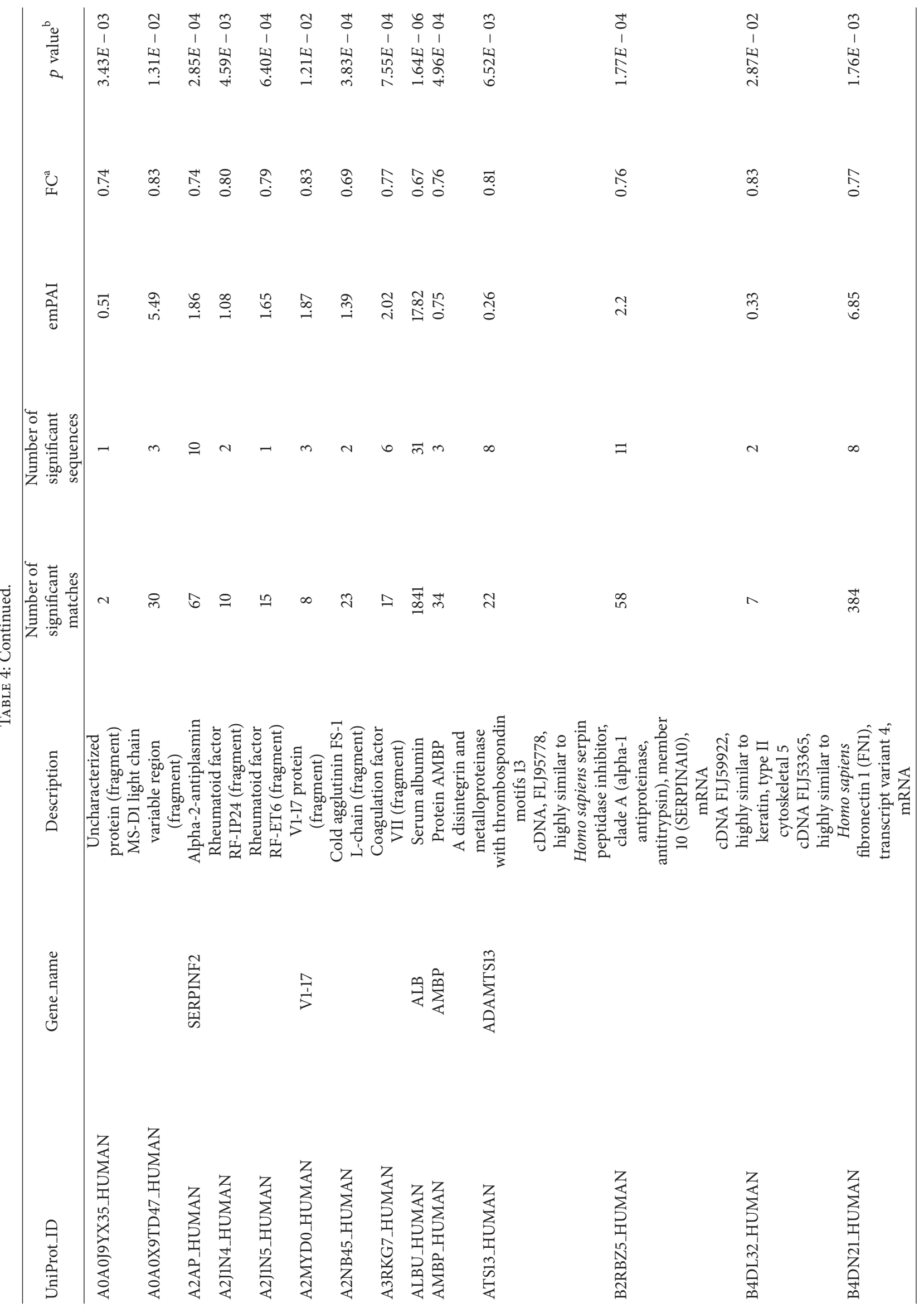




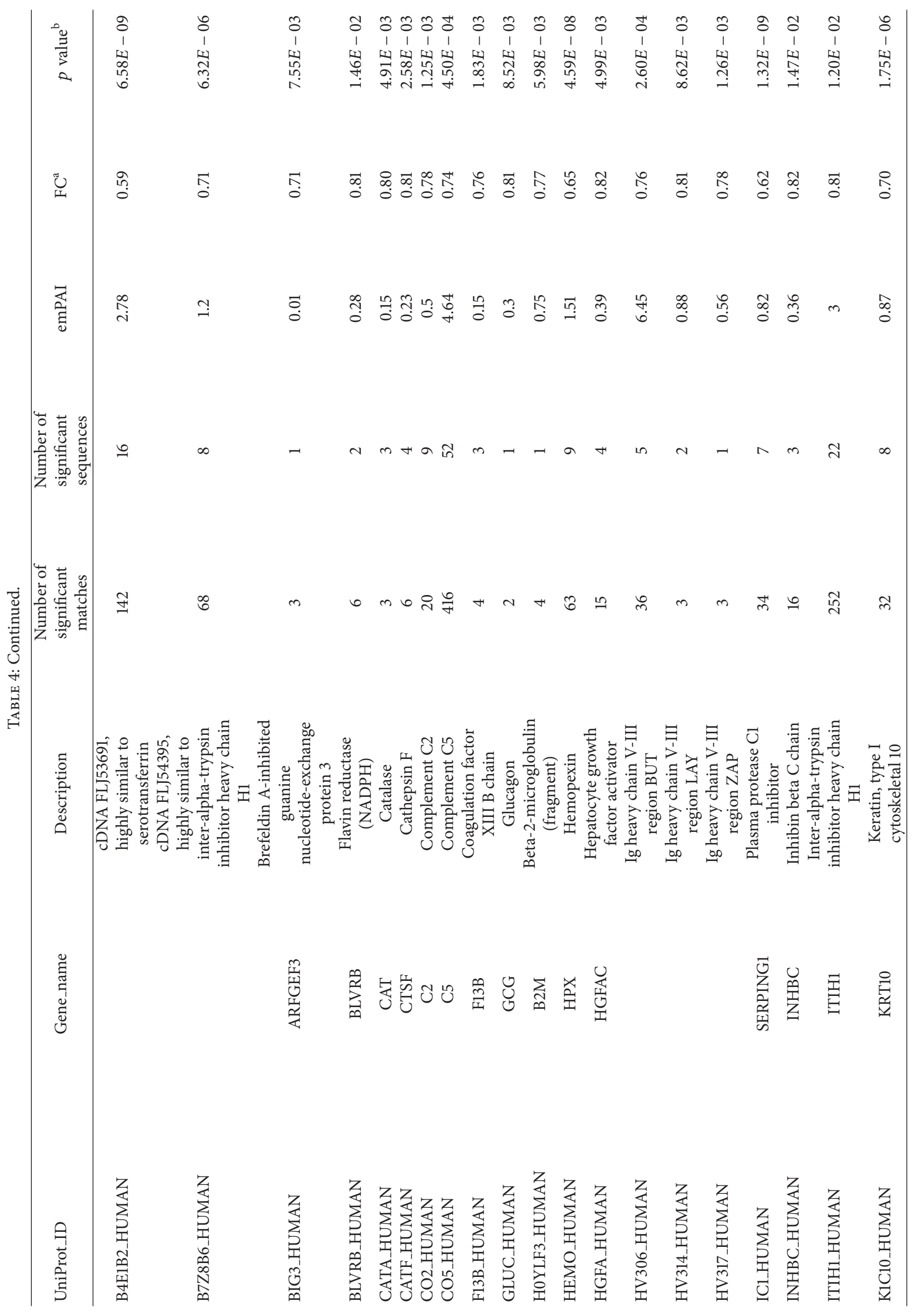




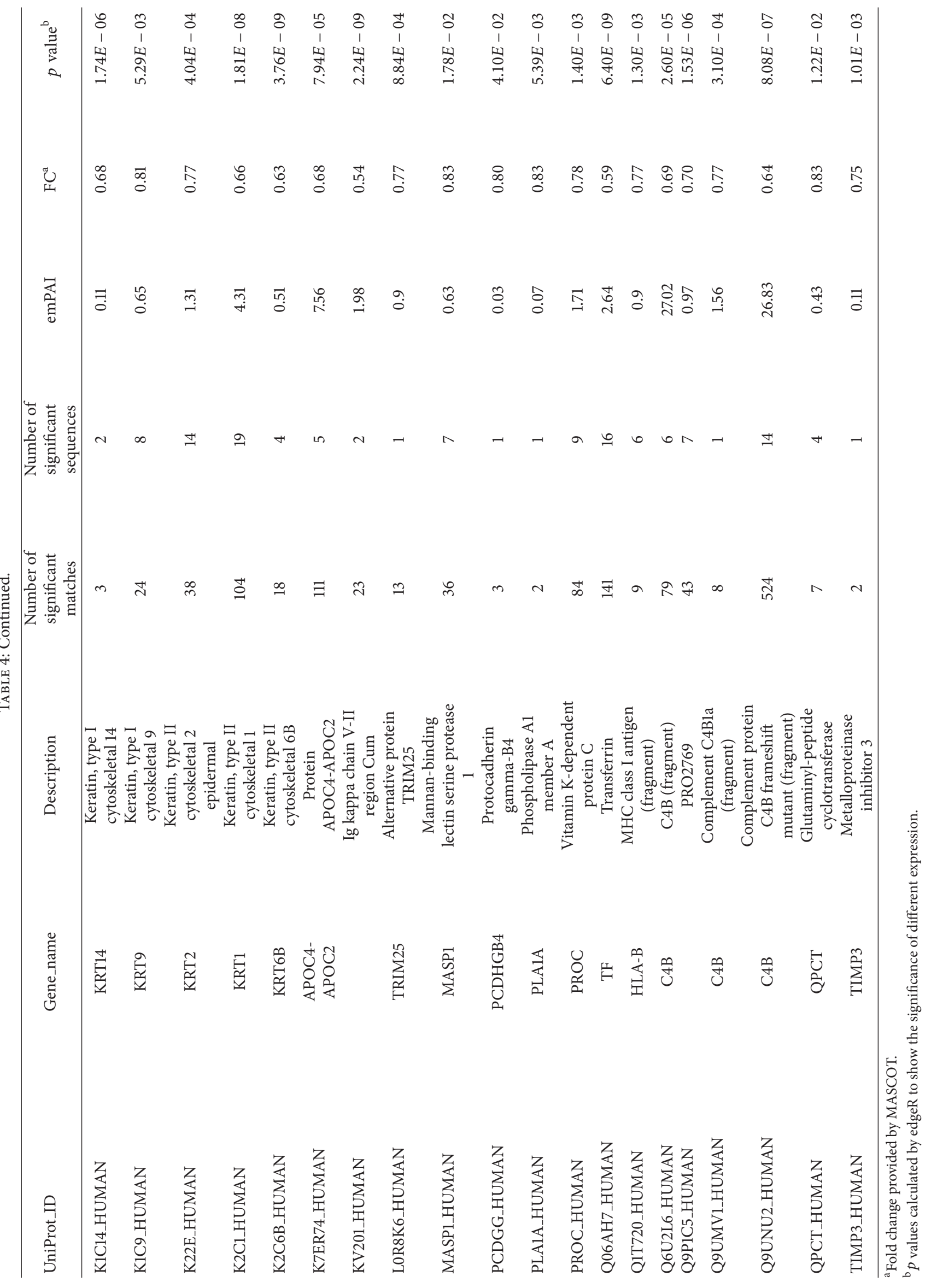




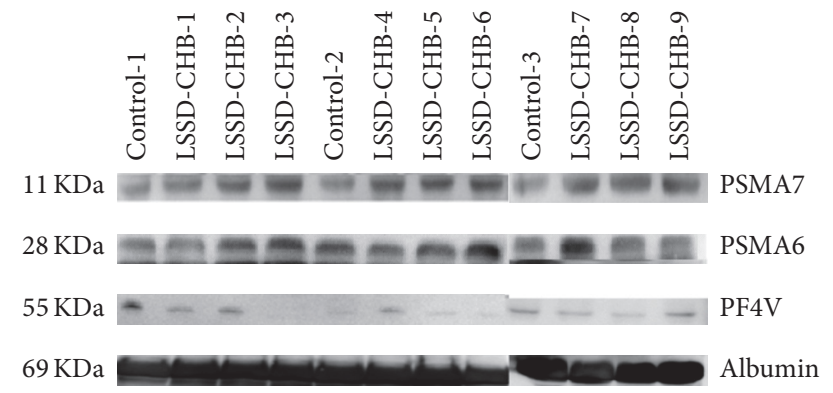

(a)

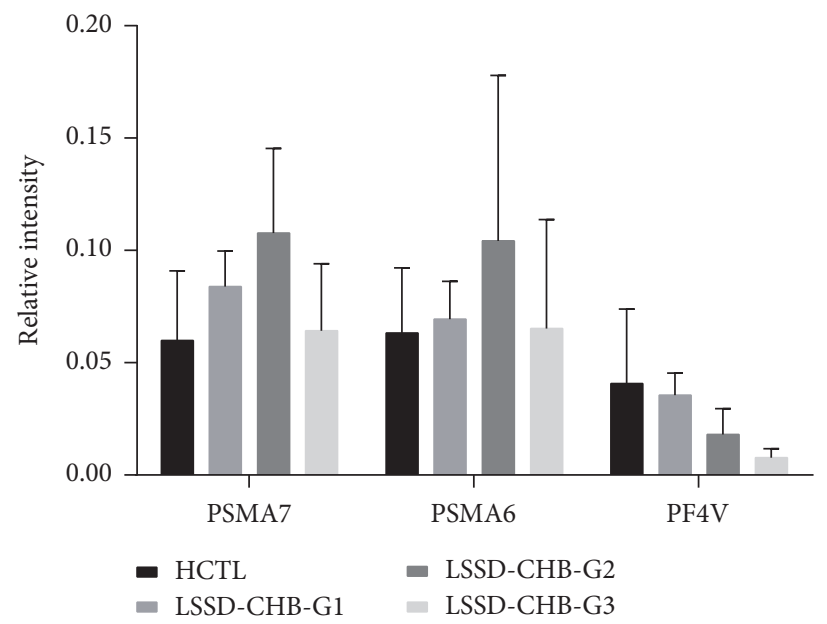

(c)

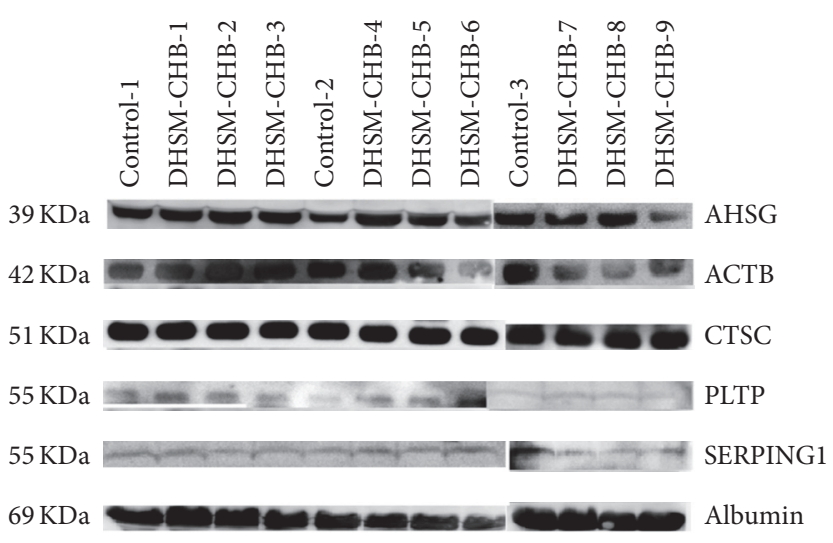

(b)

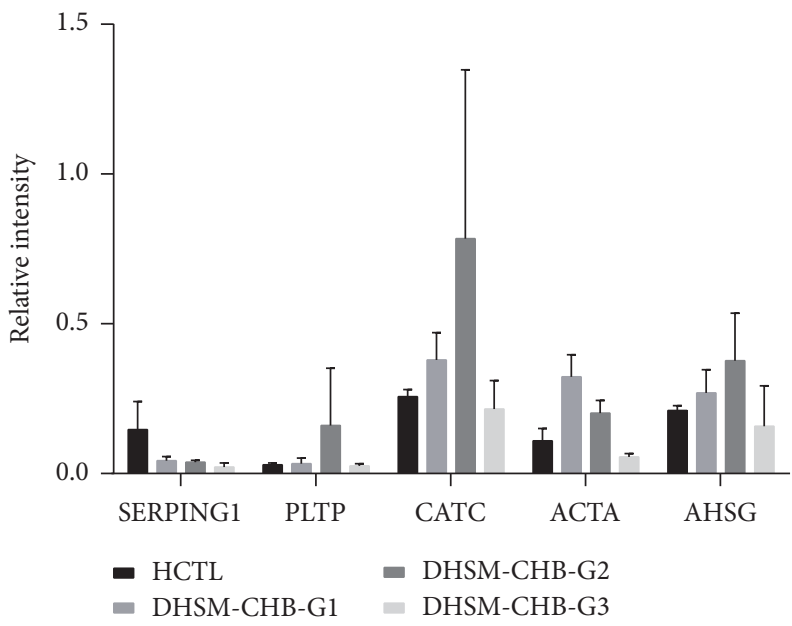

(d)

FIGURE 4: Western blot analysis. (a) Western blot analysis for PSMA7, PSMA6, and PF4 V in LSSD-CHB patients. (b) Western blot analysis for AHSG, ACTB, CTSC, PLTP, and SERPING1 in DHSM-CHB patients. Box plots of the relative intensity of candidate proteins in LSSD-CHB (c) and DHSM-CHB (d) groups.

are identified to interact with $\mathrm{HBx}$ as well [63]. Among the apolipoproteins APOA2 is a considerable biomarker because its expression is increased on both mRNA and protein levels in $\mathrm{CHB}$ patients $[14,64]$. HBx protein also interacts with heat shock proteins and enhances $\mathrm{HBx}$-mediated apoptosis [65]. A HBV-specific peptide (TVATAMG) is associated with heat shock protein and has potential for engineering tumor vaccines against hepatocellular carcinoma and chronic HBV infection [66]. Heat shock proteins like HSP27, HSP90, and GRP78 are upregulated in HBV related hepatocellular carcinoma, associated with vascular invasion and intrahepatic metastasis and have potential to be prognosis markers [67, 68]. Commonly downregulated complement proteins are important mediators of inflammation and contribute to the regulation of the immune response. $\mathrm{C} 4$, a predisposing factor to autoimmune chronic active hepatitis [69], is expressed lowly in chronic hepatitis $\mathrm{C}$ patient compared to that in controls [70]. Low serum levels of complement in viral hepatitis are associated with high titers of hepatitis-associated antigen [71]. It is said that complement proteins are related to hepatitis $\mathrm{B}$ vaccine and C4AQ0 (mutant $\mathrm{C} 4$ ) probably contribute to inefficient complement activation and failure of B cells to secret anti-HBs [72]. Our results confirmed the potential of previously reported proteins in diagnosis of patients infected by HBV.

LSSD-CHB and DHSM-CHB are two subtypes of CHB according to traditional Chinese medicine pattern classification. In this study we identified 47 and 119 differentially expressed proteins exclusively in LSSD-CHB and DHSM$\mathrm{CHB}$, respectively, which could be used as biomarkers for LSSD-CHB and DHSM-CHB patients. We showed top 5 highly expressed proteins with different expression in LSSDCHB and DHSM-CHB patients compared to HCTL group in Figure 6. Using relative expression ratio calculated by MASCOT we found mean expression levels of some proteins were close in LSSD-CHB and DHSM-CHB but with different $p$ values, such as $\mathrm{CFH}$ (complement factor $\mathrm{H}$ ), F2 (prothrombin), and FGA (fibrinogen alpha chain). As we know, prothrombin time is one of the markers of liver test; it is usually lower in HBV infected patients than in healthy people and a good marker for liver fibrosis [73, 74]. CFH functions as a cofactor in the inactivation of C3b by factor I [75], which can 


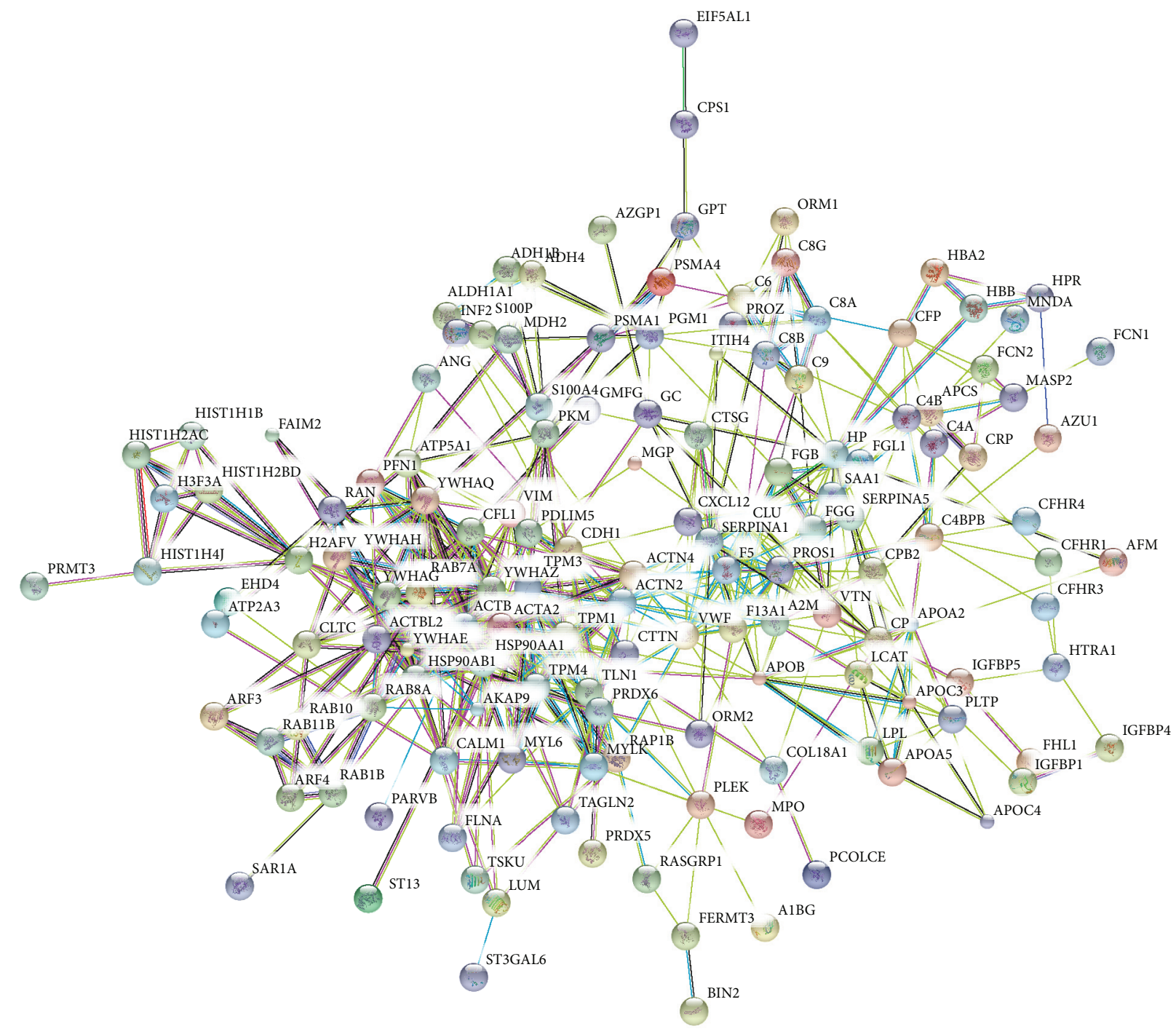

Protein-protein interactions:

_ From curated databases

— Experimentally determined

- Gene cooccurrence

_ Gene neighborhood

_ Text mining

_ Protein homology

- Coexpression

Protein homology

FIGURE 5: Protein-protein interaction network of commonly differentially expressed proteins in LSSD-CHB and DHSM-CHB patients compared with HCTL group.

interact with IgG and is moderately depressed in the serum of patients with viral hepatitis [71]. FGA has a major function in hemostasis as one of the primary components of blood clots [76]. Fibrinogen-like protein 2 (FGL2) has been identified as a potential biomarker for severity of $\mathrm{CHC}$ infection [77]. Other proteins also have been reported to be associated with $\mathrm{HBV}$ infection. LGALS3BP (lectin galactoside-binding soluble 3 binding protein isoform 1) were downregulated in LSSD-CHB patients $(\mathrm{fc}=0.71, p$ value $=2.49 E-06)$ and DHSM-CHB patients $(\mathrm{fc}=0.89, p$ value $=0.061$ ). Previous studies about LGALS3BP in CHB and HCC found its different expression on transcriptional level [78], while in current study we identified its protein was differentially expressed in $\mathrm{CHB}$ patients and had the potential to be a good marker for LSSD-CHB subtype. PON3 (serum paraoxonase/lactonase 3), which was upregulated exclusively in LSSD-CHB, might play a hepatoprotective role against histological alterations and hepatic cell apoptosis leading to liver disease [48].

DHSM-CHB specifically differentially expressed proteins like ITIH1 (inter-alpha-trypsin inhibitor heavy chain $\mathrm{H1}$ ), THBS1 (thrombospondin-1), C5 (Complement C5), and ALB (albumin) have been also reported in hepatitis viral related diseases. The expression level of ITIH1 in HCTL group was similar to that in LSSD-CHB patients $\left(\mathrm{fc}_{\mathrm{C}}=0.99, p\right.$ value $=$ 


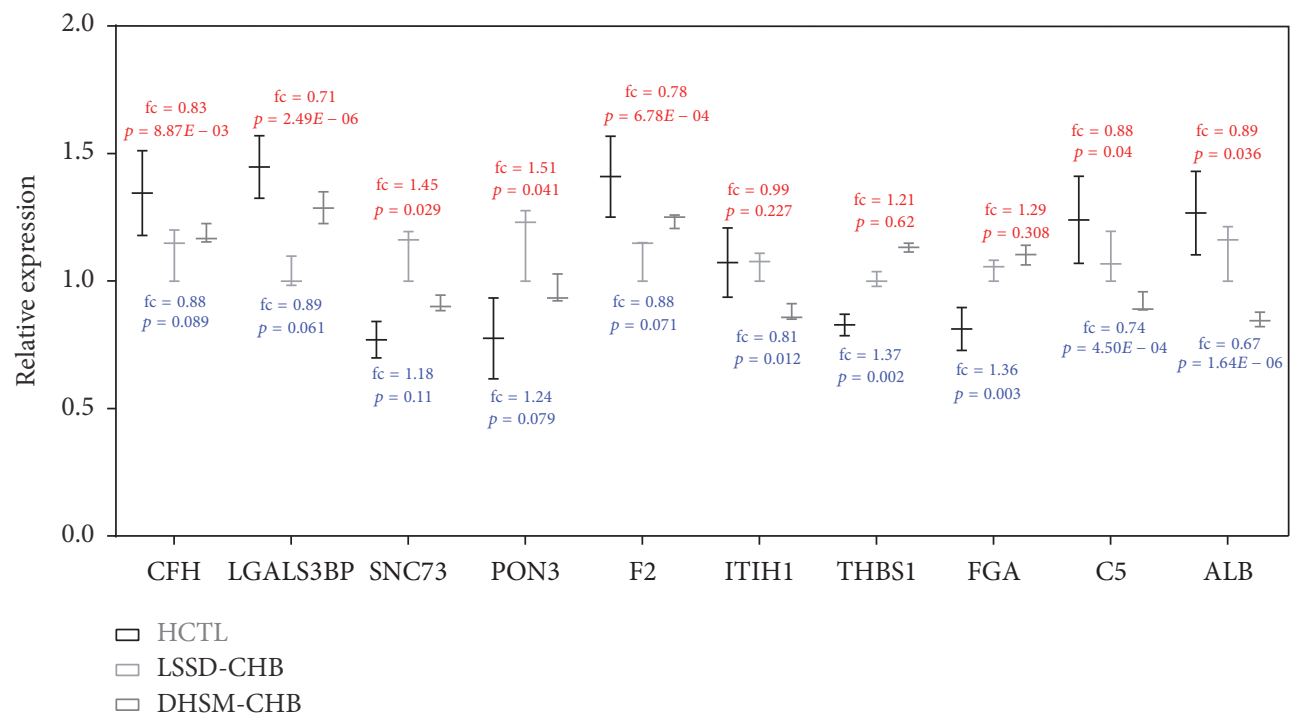

FIGURE 6: Top 5 highly expressed proteins differentially expressed in LSSD-CHB and DHSM-CHB compared to HCTL. Fold changes (fc) and $p$ values $(p)$ of them were shown in red and blue for LSSD-CHB and DHSM-CHB, respectively.

$0.227)$ but was downregulated significantly in DHSM-CHB patients $(\mathrm{fc}=0.81, p$ value $=0.012)$. The low expression of ITIH1 indicated it can be used to differ DHSM-CHB from LSSD-CHB. In addition, it has been experimented to be downregulated in HCV infected patients [79] and hepatitis C associated hepatocellular carcinoma patients [80]. It is reported that $\mathrm{HCV}$ viral proteins act directly or indirectly on THBS1 in TGF- $\beta$ pathway [81]. By noninvasive imaging the gene expression of THBS1 was upregulated in liver cancer [82]. Interestingly, ALB has been reported as an important factor to score the risk of HCC in CHB patients [83]. In our study, ALB was downregulated in both CHB subtypes but significantly exclusively in DHSM-CHB. Our results confirmed its different expression in $\mathrm{CHB}$ patients and revealed that the criteria of ALB expression in CHB patients required more patients and experiments.

Due to the fact that hepatitis B viral load in DHSMCHB patients was significantly higher than that in LSSDCHB patients, we assume HBV-DNA might be related to $\mathrm{CHB}$ patients with different syndromes and it requires further experiments. To our knowledge, this study appears to be the first iTRAQ based approach aimed at identifying leads for potential useful biomarkers of patients of CHB subtypes. The candidates identified in this study await rigorous clinical validation using large cohorts of patient samples and more experimental function analysis.

\section{Competing Interests}

The authors have declared that no competing interests exist. And Zhenhua Zhuang and Bin Yang on behalf of Chengdu Life Baseline Technology declare there are no competing interests.

\section{Authors' Contributions}

Jiankun Yang, Lichao Yang, and Quansheng Feng conceived and designed the experiments. Lichao Yang, Weilong Zhou, Sen Zhong, and Baixue Li performed the experiments. Jiankun Yang, Lichao Yang, and Maoshan Chen analyzed the data. Zhenhua Zhuang and Bin Yang contributed reagents/materials/analysis tools. Jiankun Yang, Lichao Yang, and Quansheng Feng wrote the paper. Jiankun Yang and Lichao Yang contributed equally to this work.

\section{Acknowledgments}

This study was supported by National Science and Technology Major Project of China (no. 2012ZX10005001-001).

\section{References}

[1] S. T. Goldstein, F. Zhou, S. C. Hadler, B. P. Bell, E. E. Mast, and H. S. Margolis, "A mathematical model to estimate global hepatitis B disease burden and vaccination impact," International Journal of Epidemiology, vol. 34, no. 6, pp. 1329-1339, 2005.

[2] J. J. Ott, G. A. Stevens, J. Groeger, and S. T. Wiersma, "Global epidemiology of hepatitis B virus infection: new estimates of age-specific HBsAg seroprevalence and endemicity," Vaccine, vol. 30, no. 12, pp. 2212-2219, 2012.

[3] F.-S. Wang, J.-G. Fan, Z. Zhang, B. Gao, and H.-Y. Wang, "The global burden of liver disease: the major impact of China," Hepatology, vol. 60, no. 6, pp. 2099-2108, 2014.

[4] N. H. Afdhal and D. Nunes, "Evaluation of liver fibrosis: a concise review," American Journal of Gastroenterology, vol. 99, no. 6, pp. 1160-1174, 2004.

[5] H. L.-Y. Chan, "Changing scene in hepatitis B serology interpretation," Hospital Medicine, vol. 63, no. 1, pp. 16-19, 2002. 
[6] H.-Z. Yang, J.-A. Zhao, M. Dai et al., "Traditional Chinese medicine syndromes of chronic hepatitis B with precore mutant," World Journal of Gastroenterology, vol. 11, no. 13, pp. 2004-2008, 2005.

[7] D. F. Hunt, "Personal commentary on proteomics," Journal of Proteome Research, vol. 1, no. 1, pp. 15-19, 2002.

[8] S. Wiese, K. A. Reidegeld, H. E. Meyer, and B. Warscheid, "Protein labeling by iTRAQ: a new tool for quantitative mass spectrometry in proteome research," Proteomics, vol. 7, no. 3, pp. 340-350, 2007.

[9] B. Geramizadeh, K. Janfeshan, and M. Saberfiroozi, "Serum hyaluronic acid as a noninvasive marker of hepatic fibrosis in chronic hepatitis B," Saudi Journal of Gastroenterology, vol. 14, no. 4, pp. 174-177, 2008.

[10] L. Peng, J. Liu, Y.-M. Li et al., "Serum proteomics analysis and comparisons using iTRAQ in the progression of hepatitis B," Experimental and Therapeutic Medicine, vol. 6, no. 5, pp. 11691176, 2013.

[11] A. Tong, L. Wu, Q. Lin et al., "Proteomic analysis of cellular protein alterations using a hepatitis B virus-producing cellular model," Proteomics, vol. 8, no. 10, pp. 2012-2023, 2008.

[12] D. Niu, J. Sui, J. Zhang, H. Feng, and W. N. Chen, "iTRAQcoupled 2-D LC-MS/MS analysis of protein profile associated with HBV-modulated DNA methylation," Proteomics, vol. 9, no. 15, pp. 3856-3868, 2009.

[13] C.-M. Chu, W.-C. Shyu, and Y.-F. Liaw, "Comparative studies on expression of $\alpha$-smooth muscle actin in hepatic stellate cells in chronic hepatitis B and C,' Digestive Diseases and Sciences, vol. 53, no. 5, pp. 1364-1369, 2008.

[14] Q.-Y. He, G. K. K. Lau, Y. Zhou et al., "Serum biomarkers of hepatitis B virus infected liver inflammation: A Proteomic Study," Proteomics, vol. 3, no. 5, pp. 666-674, 2003.

[15] W. Cao, Y. Zhou, Y. Li et al., "ITRAQ-based proteomic analysis of combination therapy with taurine, epigallocatechin gallate, and genistein on carbon tetrachloride-induced liver fibrosis in rats," Toxicology Letters, vol. 232, no. 1, pp. 233-245, 2015.

[16] Y. Liu, P. Liu, R. Dai et al., "Analysis of plasma proteome from cases of the different traditional Chinese medicine syndromes in patients with chronic hepatitis B," Journal of Pharmaceutical and Biomedical Analysis, vol. 59, no. 1, pp. 173-178, 2012.

[17] M.-Y. Xu, Y. Qu, X.-F. Jia et al., "Serum proteomic MRM identify peptide ions of transferrin as new fibrosis markers in chronic hepatitis B," Biomedicine and Pharmacotherapy, vol. 67, no. 7, pp. 561-567, 2013.

[18] A. Glen, C. A. Evans, C. S. Gan et al., "Eight-plex iTRAQ analysis of variant metastatic human prostate cancer cells identifies candidate biomarkers of progression: an exploratory study," Prostate, vol. 70, no. 12, pp. 1313-1332, 2010.

[19] H. Guo, C. Chen, D.-J. Lee, A. Wang, D. Gao, and N. Ren, "Coupled carbon, sulfur and nitrogen cycles of mixotrophic growth of Pseudomonas sp. C27 under denitrifying sulfide removal conditions," Bioresource Technology, vol. 171, pp. 120126, 2014.

[20] G. Yan, R. Lestari, B. Long et al., "Comparative proteomics analysis reveals L-arginine activates ethanol degradation pathways in HepG2 cells," Scientific Reports, vol. 6, Article ID 23340, 2016.

[21] D. Kessner, M. Chambers, R. Burke, D. Agus, and P. Mallick, "ProteoWizard: open source software for rapid proteomics tools development," Bioinformatics, vol. 24, no. 21, pp. 2534-2536, 2008.
[22] M. D. Robinson, D. J. McCarthy, and G. K. Smyth, "edgeR: a Bioconductor package for differential expression analysis of digital gene expression data," Bioinformatics, vol. 26, no. 1, pp. 139-140, 2010.

[23] H. Heberle, V. G. Meirelles, F. R. da Silva, G. P. Telles, and R. Minghim, "InteractiVenn: a web-based tool for the analysis of sets through Venn diagrams," BMC Bioinformatics, vol. 16, no. 1, article 169, 2015.

[24] D. W. Huang, B. T. Sherman, and R. A. Lempicki, "Systematic and integrative analysis of large gene lists using DAVID bioinformatics resources," Nature Protocols, vol. 4, no. 1, pp. 44-57, 2009.

[25] D. Szklarczyk, A. Franceschini, S. Wyder et al., "STRING v10: protein-protein interaction networks, integrated over the tree of life," Nucleic Acids Research, vol. 43, no. 1, pp. D447-D452, 2015.

[26] S. Agrawal, R. K. Dhiman, and J. K. Limdi, "Evaluation of abnormal liver function tests," Postgraduate Medical Journal, vol. 92, no. 1086, pp. 223-234, 2016.

[27] J. K. Limdi and G. M. Hyde, "Evaluation of abnormal liver function tests," Postgraduate Medical Journal, vol. 79, no. 932, pp. 307-312, 2003.

[28] F. I. Lee, "Immunoglobulins in viral hepatitis and active alcoholic liver-disease," The Lancet, vol. 286, no. 7421, pp. 1043-1046, 1965.

[29] D. C. Wong, R. H. Purcell, M. A. Sreenivasan, S. R. Prasad, and K. M. Pavri, "Epidemic and endemic hepatitis in India: evidence for a non-A, non-B hepatitis virus aetiology," The Lancet, vol. 2, no. 8200, pp. 876-879, 1980.

[30] O. Scharf, H. Golding, L. R. King et al., "Immunoglobulin G3 from polyclonal human immunodeficiency virus (HIV) immune globulin is more potent than other subclasses in neutralizing HIV type 1," Journal of Virology, vol. 75, no. 14, pp. 6558-6565, 2001.

[31] H. Gregorek, K. Dzierzanowska-Fangrat, M. Woynarowski et al., "Persistence of HBV-DNA in children with chronic hepatitis $B$ who seroconverted to anti-HBs antibodies after interferon$\alpha$ therapy: correlation with specific IgG subclass responses to HBsAg," Journal of Hepatology, vol. 42, no. 4, pp. 486-490, 2005.

[32] A. Carpentier, F. Conti, M. Carrière et al., "Analysis of gene transcription in sera during chronic hepatitis C infection," Journal of Medical Virology, vol. 81, no. 3, pp. 473-480, 2009.

[33] H. Wang, Y. Gao, X. Jin, and J. Xiao, "Expression of contactin associated protein-like 2 in a subset of hepatic progenitor cell compartment identified by gene expression profiling in hepatitis B virus-positive cirrhosis," Liver International, vol. 30, no. 1, pp. 126-138, 2010.

[34] G. Yang, W. Chu, H. Zhang et al., "Isolation and identification of mannose-binding proteins and estimation of their abundance in sera from hepatocellular carcinoma patients," Proteomics, vol. 13, no. 5, pp. 878-892, 2013.

[35] L.-N. Qi, L.-Q. Li, Y.-Y. Chen et al., "Genome-wide and differential proteomic analysis of hepatitis B virus and aflatoxin B1 related hepatocellular carcinoma in Guangxi, China," PLoS ONE, vol. 8, no. 12, Article ID e83465, 2013.

[36] P. Arbuthnot, A. Capovilla, and M. Kew, "Putative role of hepatitis B virus $\mathrm{X}$ protein in hepatocarcinogenesis: effects on apoptosis, DNA repair, mitogen-activated protein kinase and JAK/STAT pathways," Journal of Gastroenterology and Hepatology (Australia), vol. 15, no. 4, pp. 357-368, 2000.

[37] Y.-B. Deng, G. Nagae, Y. Midorikawa et al., "Identification of genes preferentially methylated in hepatitis $\mathrm{C}$ virus-related 
hepatocellular carcinoma," Cancer Science, vol. 101, no. 6, pp. 1501-1510, 2010.

[38] W. Kim, S. O. Lim, J.-S. Kim et al., "Comparison of proteome between hepatitis B virus- and hepatitis C virus-associated hepatocellular carcinoma," Clinical Cancer Research, vol. 9, no. 15, pp. 5493-5500, 2003.

[39] J.-C. Meunier, R. E. Engle, K. Faulk et al., "Evidence for cross-genotype neutralization of hepatitis $\mathrm{C}$ virus pseudoparticles and enhancement of infectivity by apolipoprotein C1," Proceedings of the National Academy of Sciences of the United States of America, vol. 102, no. 12, pp. 4560-4565, 2005.

[40] K. Hueging, R. Weller, M. Doepke et al., "Several human liver cell expressed apolipoproteins complement HCV virus production with varying efficacy conferring differential specific infectivity to released viruses," PLoS ONE, vol. 10, no. 7, Article ID e0134529, 2015.

[41] D. M. Lebensztejn, E. Skiba, J. Tobolczyk, M. E. SobaniecLotowska, and M. Kaczmarski, "Diagnostic accuracy of serum biochemical fibrosis markers in children with chronic hepatitis B evaluated by receiver operating characteristics analysis," World Journal of Gastroenterology, vol. 11, no. 45, pp. 7192-7196, 2005.

[42] R. K. Ng, C. Y. L. Lau, S. M. Y. Lee, S. K. W. Tsui, K. P. Fung, and M. M. Y. Waye, "cDNA microarray analysis of early gene expression profiles associated with hepatitis $\mathrm{B}$ virus $\mathrm{X}$ proteinmediated hepatocarcinogenesis," Biochemical and Biophysical Research Communications, vol. 322, no. 3, pp. 827-835, 2004.

[43] M. W. Smith, Z. N. Yue, M. J. Korth et al., "Hepatitis C virus and liver disease: global transcriptional profiling and identification of potential markers," Hepatology, vol. 38, no. 6, pp. 1458-1467, 2003.

[44] P. He, H.-Z. He, J. Dai et al., "The human plasma proteome: analysis of Chinese serum using shotgun strategy," Proteomics, vol. 5, no. 13, pp. 3442-3453, 2005.

[45] H.-J. Gao, Y.-J. Chen, D. Zuo et al., "Quantitative proteomic analysis for high-throughput screening of differential glycoproteins in hepatocellular carcinoma serum," Cancer Biology and Medicine, vol. 12, no. 3, pp. 246-254, 2015.

[46] A. Bertoletti and C. Ferrari, "Innate and adaptive immune responses in chronic hepatitis B virus infections: towards restoration of immune control of viral infection," Gut, vol. 61, no. 12, pp. 1754-1764, 2012.

[47] A. Bertoletti and A. J. Gehring, "The immune response during hepatitis B virus infection," Journal of General Virology, vol. 87, no. 6, pp. 1439-1449, 2006.

[48] A. García-Heredia, J. Marsillach, G. Aragonès et al., "Serum paraoxonase- 3 concentration is associated with the severity of hepatic impairment in patients with chronic liver disease," Clinical Biochemistry, vol. 44, no. 16, pp. 1320-1324, 2011.

[49] E. Suhler, W. Lin, H. L. Yin, and W. M. Lee, "Decreased plasma gelsolin concentrations in acute liver failure, myocardial infarction, septic shock, and myonecrosis," Critical Care Medicine, vol. 25, no. 4, pp. 594-598, 1997.

[50] M. Kanda, S. Nomoto, Y. Okamura et al., "Promoter hypermethylation of fibulin 1 gene is associated with tumor progression in hepatocellular carcinoma," Molecular Carcinogenesis, vol. 50, no. 8, pp. 571-579, 2011.

[51] L. D. Presser, A. Haskett, and G. Waris, "Hepatitis C virusinduced furin and thrombospondin-1 activate TGF- $\beta 1$ : role of TGF- $\beta 1$ in HCV replication," Virology, vol. 412, no. 2, pp. 284296, 2011.
[52] Y. Kuramitsu, M. Takashima, Y. Yokoyama et al., "Up-regulation of $42 \mathrm{kDa}$ tubulin alpha- 6 chain fragment in well-differentiated hepatocellular carcinoma tissues from patients infected with hepatitis C virus," Anticancer Research, vol. 31, no. 10, pp. 33313336, 2011.

[53] S. Lan, H. Wang, H. Jiang et al., "Direct interaction between $\alpha$ actinin and hepatitis C virus NS5B," FEBS Letters, vol. 554, no. 3, pp. 289-294, 2003.

[54] W.-Q. Zang, A. M. Fieno, R. A. Grant, and T. S. B. Yen, "Identification of glyceraldehyde-3-phosphate dehydrogenase as a cellular protein that binds to the hepatitis B virus posttranscriptional regulatory element," Virology, vol. 248, no. 1, pp. 4652, 1998.

[55] S.-I. Shimada, M. Kawaguchi-Miyashita, A. Kushiro et al., "Generation of polymeric immunoglobulin receptor-deficient mouse with marked reduction of secretory IgA," Journal of Immunology, vol. 163, no. 10, pp. 5367-5373, 1999.

[56] P. Strnad, T. C. Lienau, G.-Z. Tao et al., "Keratin variants associate with progression of fibrosis during chronic hepatitis C infection," Hepatology, vol. 43, no. 6, pp. 1354-1363, 2006.

[57] K. J. Cheung, K. Tilleman, D. Deforce, I. Colle, and H. Van Vlierberghe, "The HCV serum proteome: a search for fibrosis protein markers," Journal of Viral Hepatitis, vol. 16, no. 6, pp. 418-429, 2009.

[58] K. J. Cheung, L. Libbrecht, K. Tilleman, D. Deforce, I. Colle, and H. Van Vlierberghe, "Galectin-3-binding protein: a serological and histological assessment in accordance with hepatitis Crelated liver fibrosis," European Journal of Gastroenterology and Hepatology, vol. 22, no. 9, pp. 1066-1073, 2010.

[59] N. T. Zinkin, F. Grall, K. Bhaskar et al., "Serum proteomics and biomarkers in hepatocellular carcinoma and chronic liver disease," Clinical Cancer Research, vol. 14, no. 2, pp. 470-477, 2008.

[60] C.-J. Huang, Y.-H. Chen, and L.-P. Ting, "Hepatitis B virus core protein interacts with the $\mathrm{C}$-terminal region of actin-binding protein," Journal of Biomedical Science, vol. 7, no. 2, pp. 160-168, 2000.

[61] W.-S. Lin, B.-Y. Jiao, Y.-L. Wu, W.-N. Chen, and X. Lin, "Hepatitis B virus X protein blocks filamentous actin bundles by interaction with eukaryotic translation elongat ion factor 1 alpha 1," Journal of Medical Virology, vol. 84, no. 6, pp. 871-877, 2012.

[62] K.-S. Chang, J. Jiang, Z. Cai, and G. Luo, "Human apolipoprotein $\mathrm{E}$ is required for infectivity and production of hepatitis C virus in cell culture," Journal of Virology, vol. 81, no. 24, pp. 13783-13793, 2007.

[63] T. Zhang, N. Xie, W. He et al., "An integrated proteomics and bioinformatics analyses of hepatitis B virus $\mathrm{X}$ interacting proteins and identification of a novel interactor apoA-I," Journal of Proteomics, vol. 84, pp. 92-105, 2013.

[64] X. Zhang, Z. Zhang, F. Dai et al., "Comparison of circulating, hepatocyte specific messenger RNA and microRNA as biomarkers for chronic hepatitis B and C," PLoS ONE, vol. 9, no. 3, Article ID e92112, 2014.

[65] Y. Tanaka, F. Kanai, T. Kawakami et al., "Interaction of the hepatitis $\mathrm{B}$ virus $\mathrm{X}$ protein $(\mathrm{HBx})$ with heat shock protein 60 enhances HBx-mediated apoptosis," Biochemical and Biophysical Research Communications, vol. 318, no. 2, pp. 461-469, 2004.

[66] S.-D. Meng, T. Gao, G. F. Gao, and P. Tien, "HBV-specific peptide associated with heat-shock protein gp96," The Lancet, vol. 357, no. 9255, pp. 528-529, 2001. 
[67] S. O. Lim, S. G. Park, J.-H. Yoo et al., "Expression of heat shock proteins (HSP27, HSP60, HSP70, HSP90, GRP78, GRP94) in hepatitis B virus-related hepatocellular carcinomas and dysplastic nodules," World Journal of Gastroenterology, vol. 11, no. 14, pp. 2072-2079, 2005.

[68] J. M. Luk, C.-T. Lam, A. F. M. Siu et al., "Proteomic profiling of hepatocellular carcinoma in Chinese cohort reveals heatshock proteins (Hsp27, Hsp70, GRP78) up-regulation and their associated prognostic values," Proteomics, vol. 6, no. 3, pp. 10491057, 2006.

[69] D. Vergani, V. Larcher, E. Davies et al., "Genetically determined low c4: a predisposing factor to autoimmune chronic active hepatitis," The Lancet, vol. 326, no. 8450, pp. 294-298, 1985.

[70] B. E. Behairy, G. M. El-Mashad, R. S. Abd-Elghany, E. M. Ghoneim, and M. M. Sira, "Serum complement C4a and its relation to liver fibrosis in children with chronic hepatitis C," World Journal of Hepatology, vol. 5, no. 8, pp. 445-451, 2013.

[71] E. Alpert, K. J. Isselbacher, and P. H. Schur, "The pathogenesis of arthritis associated with viral hepatitis. Complementcomponent studies," The New England Journal of Medicine, vol. 285 , no. 4 , pp. $185-189,1971$.

[72] T. Höhler, B. Stradmann-Bellinghausen, R. Starke et al., "C4A deficiency and nonresponse to hepatitis B vaccination," Journal of Hepatology, vol. 37, no. 3, pp. 387-392, 2002.

[73] C.-T. Wai, C. L. Cheng, A. Wee et al., "Non-invasive models for predicting histology in patients with chronic hepatitis B," Liver International, vol. 26, no. 6, pp. 666-672, 2006.

[74] M.-D. Zeng, L.-G. Lu, Y.-M. Mao et al., "Prediction of significant fibrosis in HBeAg-positive patients with chronic hepatitis B by a noninvasive model," Hepatology, vol. 42, no. 6, pp. 1437-1445, 2005.

[75] T. F. Schulz, W. Schwable, K. K. Stanley, E. Weiss, and M. P. Dierich, "Human complement factor H: Isolation of cDNA clones and partial cDNA sequence of the $38-\mathrm{kDa}$ tryptic fragment containing the binding site for C3b," European Journal of Immunology, vol. 16, no. 11, pp. 1351-1355, 1986.

[76] J. A. Kant, S. T. Lord, and G. R. Crabtree, "Partial mRNA sequences for human A alpha, B beta, and gamma fibrinogen chains: evolutionary and functional implications," Proceedings of the National Academy of Sciences of the United States of America, vol. 80, no. 13, pp. 3953-3957, 1983.

[77] K. Foerster, A. Helmy, Y. Zhu et al., "The novel immunoregulatory molecule FGL2: a potential biomarker for severity of chronic hepatitis C virus infection," Journal of Hepatology, vol. 53, no. 4, pp. 608-615, 2010.

[78] Y.-Y. Lu, Q.-L. Chen, Y. Guan et al., “Transcriptional profiling and co-expression network analysis identifies potential biomarkers to differentiate chronic hepatitis B and the caused cirrhosis," Molecular BioSystems, vol. 10, no. 5, pp. 1117-1125, 2014.

[79] F. Caillot, M. Hiron, O. Goria et al., "Novel serum markers of fibrosis progression for the follow-up of hepatitis $\mathrm{C}$ virusinfected patients," American Journal of Pathology, vol. 175, no. 1, pp. 46-53, 2009.

[80] H. G. Hass, J. Jobst, U. Vogel, M. Scheurlen, and O. Nehls, "Overexpression of tumor-associated trypsin inhibitor (SPINK1/TATI) in hepatitis C-associated hepatocellular carcinoma: Potential implications for viral hepatocarcinogenesis," Oncology Research and Treatment, vol. 37, no. 12, pp. 732-738, 2014.

[81] W. Yuan, T. Huang, J. Yu et al., "Comparative analysis of viral protein interaction networks in Hepatitis B Virus and Hepatitis
C Virus infected HCC, Biochimica et Biophysica Acta B, vol. 1844, no. 1, pp. 271-279, 2014.

[82] E. Segal, C. B. Sirlin, C. Ooi et al., "Decoding global gene expression programs in liver cancer by noninvasive imaging," Nature Biotechnology, vol. 25, no. 6, pp. 675-680, 2007.

[83] G. L.-H. Wong, H. L.-Y. Chan, C. K.-Y. Wong et al., "Liver stiffness-based optimization of hepatocellular carcinoma risk score in patients with chronic hepatitis B," Journal of Hepatology, vol. 60, no. 2, pp. 339-345, 2014. 


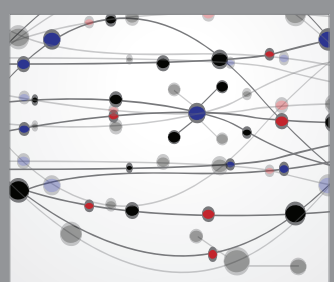

The Scientific World Journal
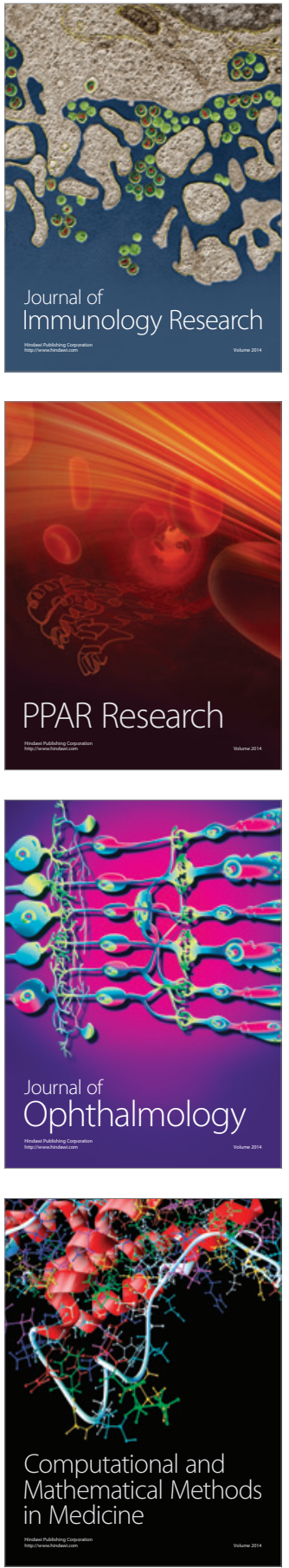

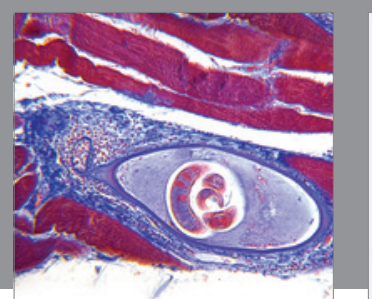

Gastroenterology Research and Practice

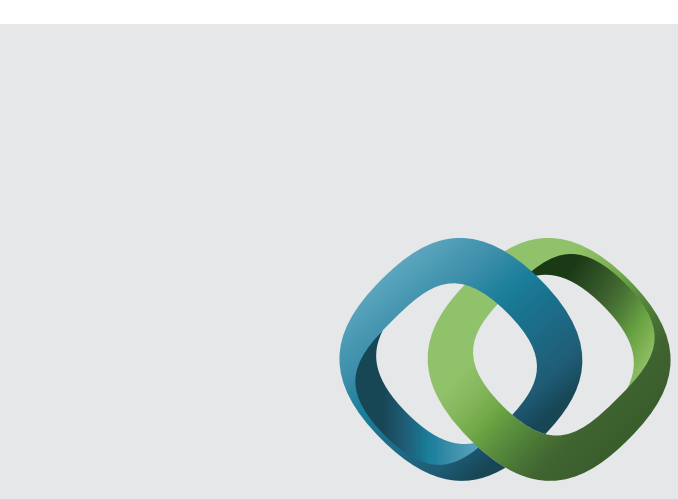

\section{Hindawi}

Submit your manuscripts at

http://www.hindawi.com
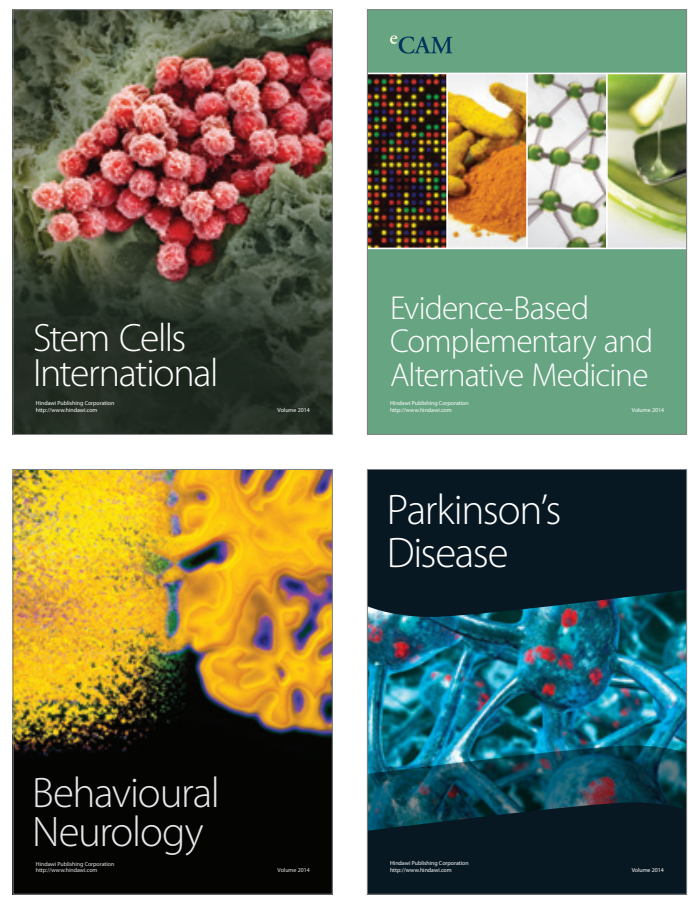
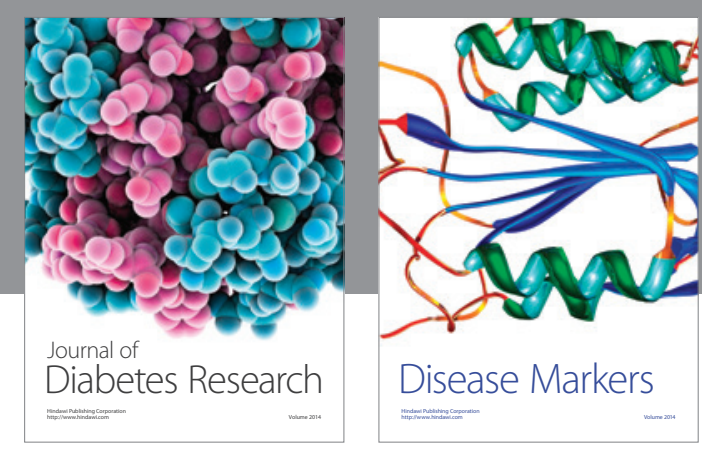

Disease Markers
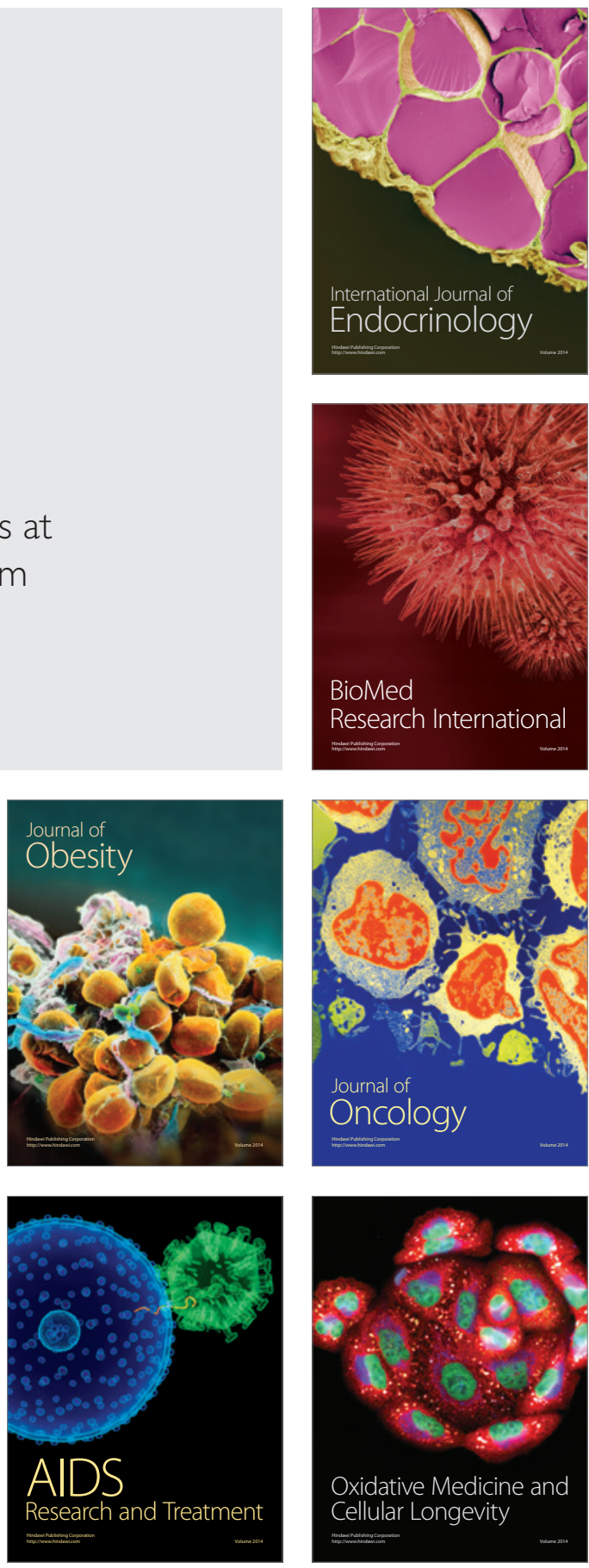